\title{
Investigation of Spin Coating Cerium-Doped Hydroxyapatite Thin Films with Antifungal Properties
}

\author{
Simona Liliana Iconaru ${ }^{1}$ * , Mihai Valentin Predoi ${ }^{2}$, Patrick Chapon ${ }^{3}$, Sofia Gaiaschi ${ }^{3}$, Krzysztof Rokosz ${ }^{4}(\mathbb{}$, \\ Steinar Raaen ${ }^{5}$, Mikael Motelica-Heino ${ }^{6}$ and Daniela Predoi ${ }^{1, *}$ \\ 1 National Institute of Materials Physics, Atomistilor Street, No. 405A, P.O. Box MG 07, \\ 077125 Magurele, Romania \\ 2 Department of Mechanics, University Politehnica of Bucharest, BN 002, 313 Splaiul Independentei, Sector 6, \\ 060042 Bucharest, Romania; predoi@gmail.com \\ 3 HORIBA Jobin Yvon S.A.S., 6-18, Rue du Canal, CEDEX, 91165 Longjumeau, France; \\ patrick.chapon@horiba.com (P.C.); sofia.gaiaschi@horiba.com (S.G.) \\ 4 Division of Surface Electrochemistry \& Technology, Faculty of Mechanical Engineering, Koszalin University \\ of Technology, Racławicka 15-17, PL 75-620 Koszalin, Poland; rokosz@tu.koszalin.pl \\ 5 Department of Physics, Norwegian University of Science and Technology (NTNU), Realfagbygget E3-124 \\ Høgskoleringen 5, NO 7491 Trondheim, Norway; steinar.raaen@ntnu.no \\ 6 ISTO, UMR 7327 CNRS Université d'Orléans, 1A rue de la Férollerie, 45071 Orléans, France; \\ mikael.motelica@univ-orleans.fr \\ * Correspondence: simonaiconaru@gmail.com (S.L.I.); dpredoi@gmail.com (D.P.)
}

check for updates

Citation: Iconaru, S.L.; Predoi, M.V.; Chapon, P.; Gaiaschi, S.; Rokosz, K.;

Raaen, S.; Motelica-Heino, M.; Predoi, D. Investigation of Spin Coating Cerium-Doped Hydroxyapatite Thin Films with Antifungal Properties. Coatings 2021, 11, 464. https:// doi.org/10.3390/coatings11040464

Academic Editor: Roman

A. Surmenev

Received: 24 March 2021

Accepted: 13 April 2021

Published: 16 April 2021

Publisher's Note: MDPI stays neutral with regard to jurisdictional claims in published maps and institutional affiliations.

Copyright: (c) 2021 by the authors. Licensee MDPI, Basel, Switzerland. This article is an open access article distributed under the terms and conditions of the Creative Commons Attribution (CC BY) license (https:/ / creativecommons.org/licenses/by/ $4.0 /)$.
Abstract: In this study, the cerium-doped hydroxyapatite $\left(\mathrm{Ca}_{10-x} \mathrm{Ce}_{x}\left(\mathrm{PO}_{4}\right)_{6}(\mathrm{OH})_{2}\right.$ with $x_{\mathrm{Ce}}=0.1$, 10Ce-HAp) coatings obtained by the spin coating method were presented for the first time. The stability of the 10Ce-HAp suspension particles used in the preparation of coatings was evaluated by ultrasonic studies, transmission electron microscopy (TEM), X-ray diffraction (XRD), and scanning electron microscopy (SEM). The surface morphology of the 10Ce-HAp coating was studied by SEM and atomic force microscopy (AFM) techniques. The obtained 10Ce-HAp coatings were uniform and without cracks or unevenness. Glow discharge optical emission spectroscopy (GDOES) and X-ray photoelectron spectroscopy (XPS) were used for the investigation of fine chemical depth profiling. The antifungal properties of the HAp and 10Ce-HAp suspensions and coatings were assessed using Candida albicans ATCC 10231 (C. albicans) fungal strain. The quantitative antifungal assays demonstrated that both 10Ce-HAp suspensions and coatings exhibited strong antifungal properties and that they successfully inhibited the development and adherence of $C$. albicans fungal cells for all the tested time intervals. The scanning electron microscopy (SEM) and confocal laser scanning microscopy (CLSM) visualization of the C. albicans fungal cells adherence to the 10Ce-HAp surface also demonstrated their strong inhibitory effects. In addition, the qualitative assays also suggested that the 10Ce-HAp coatings successfully stopped the biofilm formation.

Keywords: cerium; hydroxyapatite; spin coating; antifungal properties

\section{Introduction}

In the last years, the prevalence of hospital-related infections caused by drug resistant microorganisms was high. The most frequent infections were the ones associated with the use of catheters and the ones that appear at surgical sites [1-3]. The most common microorganisms known to be responsible for these types of infections are Staphylococcus aureus, Enterococcus spp., Escherichia coli, methicillin-resistant Staphylococcus aureus (MRSA), and the yeast Candida albicans. Drug-resistant microorganisms cause more than $20 \%$ of these infections. Candida albicans is the most common species of fungi involved in hospitalassociated infections. The yeast, C. albicans is a dimorphic and commensal fungus, and it is commonly found in the human gut flora. It usually colonizes the skin, but it is also found in the gastrointestinal tract and mouth in more than $40 \%$ of healthy adults, and 
it is known to survive outside the human body [3-6]. Nowadays, the fungal infections in patients pre and post operatory has risen to a greater number than ever, and it is growing every year throughout the world. These facts together with the emergence of microorganisms resistant to conventional antibiotics have encouraged the need for the development of newly antifungal agents that could be able to prevent and/or eradicate these microorganisms. Therefore, in the last few years, great attention has been awarded to the use of materials science to synthesize new materials with antimicrobial properties that could be used in the development of new antimicrobial devices with a great impact in the prevention and treatment of infections. Recently, studies have evidenced that nanomaterials possess great potential in the development of new compounds that could interfere in the prevention and treatment of multidrug-resistant microbial infections [7-10]. One of the most studied materials due to its impressive properties such as nanometric size, high surface area, biocompatibility, osteoconductivity, and surface reactivity is hydroxyapatite (HAp) [11,12]. Despite the numerous extraordinary properties exhibited by nanometric hydroxyapatite nanoparticles, pure bulk HAp has some disadvantages such as reduced fatigue resistance, low toughness, poor bending strength, slow dissolution rate, brittleness, and also, HAp does not exhibit any antimicrobial activity [12-17]. A method to resolve these weaknesses partially or totally has been the use of ionic substitution using metal ions such as $\mathrm{Ag}^{+}, \mathrm{Cu}^{2+}, \mathrm{Zn}^{2+}[17], \mathrm{Ce}^{3+}[18], \mathrm{Mg}^{2+}[15], \mathrm{Zn}^{2+}$ [17], $\mathrm{La}^{3+}[16], \mathrm{Sr}^{2+}[19], \mathrm{Al}^{3+}$ [20], $\mathrm{K}^{+}$[21], etc., that could confer improved properties to HAp such as mechanical stability, cytocompatibility, solubility, bioactivity, and also antimicrobial activity [12-21]. Cerium is a rare-earth metal and does not accumulate in the food chain and has low to moderate toxicity [14-17]. Cerium is known for its properties of lowering the cholesterol levels, blood pressure, and to prevent the risk of blood cloth apparition in humans. Moreover, cerium nitrate has been used as an antimicrobial treatment for burn injuries. Moreover, cerium could be found such as $\mathrm{Ce}^{3+}$ and $\mathrm{Ce}^{4+}$, and it has the unique ability to swap between oxidation states that confers its antibacterial and antioxidant properties [18]. In the last years, cerium has been widely used in medicine in various applications such as catheters, treatment of burn wounds, and in dentistry [22,23]. Therefore, the obtaining of novel cerium-doped hydroxyapatite materials for the development of medical device coatings could contribute with important advances in the area of antimicrobial agents. In a previous study, we presented cerium-coated hydroxyapatite $\left(x_{\mathrm{Ce}}=0.05\right)$ coatings obtained by plasma by RF magnetron sputtering [24].

Through this study, we aimed to bring additional information on the coatings based on cerium-doped hydroxyapatite $\left(x_{\mathrm{Ce}}=0.1\right)$. This research presents for the first time both physicochemical and antifungal properties of cerium-doped hydroxyapatite coatings obtained by the spin coating method.

The advantage of the spin coating method is to achieve smooth covered surfaces without unevenness and cracks. The stability of the suspension plays an important role in achieving uniform layers. Moreover, this method can ensure the uniformity and thickness of the coatings. In this study, we will analyze the physicochemical properties and the antifungal activity of the coatings obtained from the 10Ce-HAp suspension.

\section{Materials and Methods}

\subsection{Materials}

In order to obtained 10Ce-HAp coatings, the ammonium hydrogen phosphate, $\left(\mathrm{NH}_{4}\right)_{2} \mathrm{HPO}_{4}$ (Sigma Aldrich, St. Louis, MO, USA, $\geq 99.0 \%$ ), calcium nitrate tetrahydrate, $\mathrm{Ca}\left(\mathrm{NO}_{3}\right)_{2} \cdot 4 \mathrm{H}_{2} \mathrm{O}$ (Sigma Aldrich, St. Louis, MO, USA, $\geq 99.0 \%$ ), cerium nitrate hexahydrate, $\mathrm{Ce}\left(\mathrm{NO}_{3}\right)_{3} \cdot 6 \mathrm{H}_{2} \mathrm{O}$ (Alpha Aesar, Landau, Germany, $99.97 \%$ purity), ammonium hydroxide, $\mathrm{NH}_{4} \mathrm{OH}$ [Sigma Aldrich, St. Louis, MO, USA, 25\% $\mathrm{NH}_{3}$ in $\mathrm{H}_{2} \mathrm{O}(\mathrm{T})$ ], ethanol absolute, and double-distilled water were used to achieve $\mathrm{Ca}_{10-x} \mathrm{Ce}_{x}\left(\mathrm{PO}_{4}\right)_{6}(\mathrm{OH})_{2}$ suspension by the sol-gel method were $x_{\mathrm{Ce}}=0.1$, hereinafter referred to as 10Ce-HAp. 


\subsection{Cerium Doped Hydroxyapatite (10Ce-HAp) Coatings by Spin Coating Method}

Specific amounts of $\left(\mathrm{NH}_{4}\right)_{2} \mathrm{HPO}_{4}, \mathrm{Ca}\left(\mathrm{NO}_{3}\right)_{2} \cdot 4 \mathrm{H}_{2} \mathrm{O}$, and $\mathrm{Ce}\left(\mathrm{NO}_{3}\right)_{2} \cdot 6 \mathrm{H}_{2} \mathrm{O}$ were dissolved in absolute ethanol. These three solutions were mixed drop by drop in order to obtain the $\mathrm{Ca}_{10-x} \mathrm{Ce}_{x}\left(\mathrm{PO}_{4}\right)_{6}(\mathrm{OH})_{2}$ sol with $x_{\mathrm{Ce}}=0$ and $x_{\mathrm{Ce}}=0.1$ and $\mathrm{Ca} / \mathrm{P}$ molar ratio of 1.67. The mixture was stirred for $8 \mathrm{~h}$ at $100^{\circ} \mathrm{C}$. After that, the mixture was stirred at room temperature for $24 \mathrm{~h}$. The resultant 10Ce-HAp sol was closely capped and aged for $24 \mathrm{~h}$ at $40{ }^{\circ} \mathrm{C}$. The $\mathrm{Si}$ was used as substrate. The dimensions of the substrate samples are $5 \times 5 \mathrm{~mm}$. The substrate samples were ultra-sonically degreased with acetone. After degreasing, the substrate samples were washed with double-distilled water and dried at $40{ }^{\circ} \mathrm{C}$ during $15 \mathrm{~min}$. The spin coating process was performed by controlled centrifugation of the Si substrate loaded with 10Ce-HAp soil, resulting in film formation [25]. The evaporation process was accelerated by drying the samples obtained in an oven at a temperature of $100{ }^{\circ} \mathrm{C}$ in air for $4 \mathrm{~h}$. Subsequently, 10Ce-HAp deposited film was subjected to an additional heat treatment at $500{ }^{\circ} \mathrm{C}$ in air.

\subsection{Characterization Methods}

The stability of the 10Ce-HAp composite was evaluated through ultrasonic studies that were in agreement with previous studies [26-28]. Transmission electron microscope (TEM) investigations were conducted with a CM 20 (Philips FEI, Eindhoven, The Netherlands) equipped with a Lab6 instrument. A drop of the 10Ce-HAp suspension was dropped onto a carbon film-coated copper grid and dried for $12 \mathrm{~h}$ under nitrogen atmosphere in a desiccator. X-ray diffraction (XRD) patterns of 10Ce-HAp were accumulated using a Bruker D8 Advance diffractometer with nickel-filtered $\mathrm{Cu} \mathrm{K} \alpha(\lambda=1.5418 \AA)$ radiation (Billerica, MA, USA). The average particle size is calculated using the Debye-Scherrer Equation (1):

$$
\beta=(0.94 \cdot \lambda) /(D \cos \theta)
$$

where $\beta$ is the full-width at half-maximum (FWHM), $\lambda$ is the $\mathrm{X}$-ray wavelength, $\mathrm{D}$ is the crystal size, and $\theta$ is the Bragg angle for the reflection (002). The morphology of the 10Ce-HAp was investigated by scanning electron microscopy (SEM) using a Hitachi S4500 instrument (Hitachi, Tokyo, Japan). The chemical constituents of the 10Ce-HAp samples (suspension and coating) were determined by energy-dispersive X-ray spectroscopy (EDS). The 3D representation of the 2D SEM topographies was done using Image J software (ImageJ 1.51j8, National Institutes of Health, Bethesda, MD, USA) [29].

Information about the coating's surface morphology was obtained by performing atomic force microscopy (AFM) measurements. The data were recorded in non-contact mode at room temperature, with the aid of a NT-MDT NTEGRA Probe NanoLaboratory system (NT-MDT, Moscow, Russia). The topographic images were recorded with a silicon NT-MDT NSG01 $35 \mathrm{~nm}$ gold-coated cantilever on surface areas of $5 \times 5 \mu^{2}$. The analysis of the 2D topographies and the 3D data processing were performed using Gwyddion 2.55 software [30].

The X-ray photoelectron spectroscopy (XPS) analysis was conducted using an SES 2002 instrument (Scienta Omicron, Taunusstein, Germany) using a monochromatic Al K(alpha) $(\mathrm{h} v=1486.6 \mathrm{eV}) \mathrm{X}$-ray source (Scienta Omicron, $18.7 \mathrm{~mA}, 13.02 \mathrm{kV})$. Scans analyses were carried out with an analysis area of $1 \times 3 \mathrm{~mm}$ and a pass energy of $500 \mathrm{eV}$ with the energy step $0.2 \mathrm{eV}$ and step time $200 \mathrm{~ms}$. The binding energy of the spectrometer has been calibrated by the position of the Fermi level on a clean metallic sample. The power supplies were stable and of high accuracy. The experiments were carried out in an ultra-highvacuum system with a base pressure of about 6.10 $8 \mathrm{~Pa}$. The XPS spectra were recorded in normal emission. For the XPS analyses, the CasaXPS 2.3.14 software (Shirley background type) [31] with the help of XPS tables [32,33] was used. All the binding energy values presented in that paper were charge corrected to C $1 \mathrm{~s}$ at $284.8 \mathrm{eV}$.

The qualitative investigation of the elemental depth profiles of the 10Ce-HAp coatings was performed using a GD-Profiler 2 instrument (Horiba Jobin Yvon, Longjumeau, France). The procedure and parameters were the same as in our previous works $[24,34,35]$. 


\subsection{In Vitro Antifungal Assay}

The antifungal properties of the 10Ce-HAp and HAp suspension and coatings against one of the most spread fungi cells was assessed with the aid of the reference fungal strain Candida albicans ATCC 10231. The strain was acquired from the American Type Culture Collection (ATCC, Manassas, VA, USA). The antifungal assays were performed as previously reported [36]. The qualitative assays of the fungal cells adherence, proliferation, and development was done by scanning electron microscopy (SEM) and confocal laser scanning microscopy (CLSM) studies. For this purpose, the 10Ce-HAp coatings were incubated with a C. albicans ATCC 10.231 culture medium for 24, 48, and $72 \mathrm{~h}$, removed from the fungal medium, washed with sterile saline solution, and then fixed with cold methanol. For the CLSM visualization, the samples were stained in the dark using propidium iodide (PI). The CLSM visualization was realized in reflection and fluorescence modes with the aid of a Leica TCS-SP confocal microscope (Wetzlar, Germany). The Leica confocal microscope was equipped with a PL FLUOTAR (40_ NA 0.7) objective and an Ar ion laser with a laser line at $488 \mathrm{~nm}$.

The in vitro quantitative analysis of the antifungal properties of both HAp and 10CeHAp suspensions and coatings was performed with an adapted method (E2149-10; ASTM International) [37,38], as previously described [39]. The experiments were done in triplicate, and the results were expressed as mean \pm SD. Complementary information was obtained by performing the 3D representation of the SEM and CLSM images using Image J software (ImageJ 1.51j8, National Institutes of Health, Bethesda, MD, USA) [29].

\section{Results and Discussions}

In order to obtain coatings with uniform and smooth surfaces by the dip coating method, the stability of the suspension used in the process of obtaining thin layers plays an important role. Information on the stability of the 10Ce-HAp suspension used to obtain coatings is presented in Figure 1. The non-destructive ultrasound studies provided us with information on the stability of the 10Ce-HAp suspension, as can be seen in Figure 1a,b. The stability of the analyzed sample was related to the stability of the double-distilled water considered as the reference fluid (water is the fluid with the highest stability). Figure 1a showed the frequency spectrum of the first transmitted echo relative to the first echo transmitted by water (reference fluid for the best stability). The lowest curves correspond to the first sedimentation period, and the upper ones correspond to the asymptotic sedimentation of the 10Ce-HAp suspension, during which the amplitudes increase. The amplitude peaks at $4 \mathrm{MHz}$ is a feature of these transducers. It is clearly observed that the frequency spectrum through the studied suspension has the same behavior as that of the double distilled water used as reference fluid. Another important information of the 10Ce-HAp suspension is the frequency attenuation dependence. Figure $1 \mathrm{~b}$ shows the frequency attenuation dependence for both the 10Ce-HAp suspension and the reference fluid. It was observed that for the 10Ce-HAp suspension, the attenuation is lower at 3 and $4 \mathrm{MHz}$ compared to the one at $2 \mathrm{MHz}$. This behavior could be given by the size of the particles. It can be observed that the attenuation is higher in the case of the studied suspension (7.8-11.5 nepper $/ \mathrm{m}$ ) compared to the reference fluid (0.3-1.3 nepper $/ \mathrm{m})$. Much higher attenuation values in the case of the 10Ce-HAp suspension show a strong dispersion of the waves by the solid particles. The frequency spectrum of the first transmitted echo of HAp relative to the first echo transmitted by water (reference fluid for the best stability) was presented in Figure 1c. The frequency attenuation dependence for both the HAp suspension and the reference fluid is shown in Figure 1d. The behavior of the HAp suspension was similar to that of the double-distilled water used as the reference fluid. 

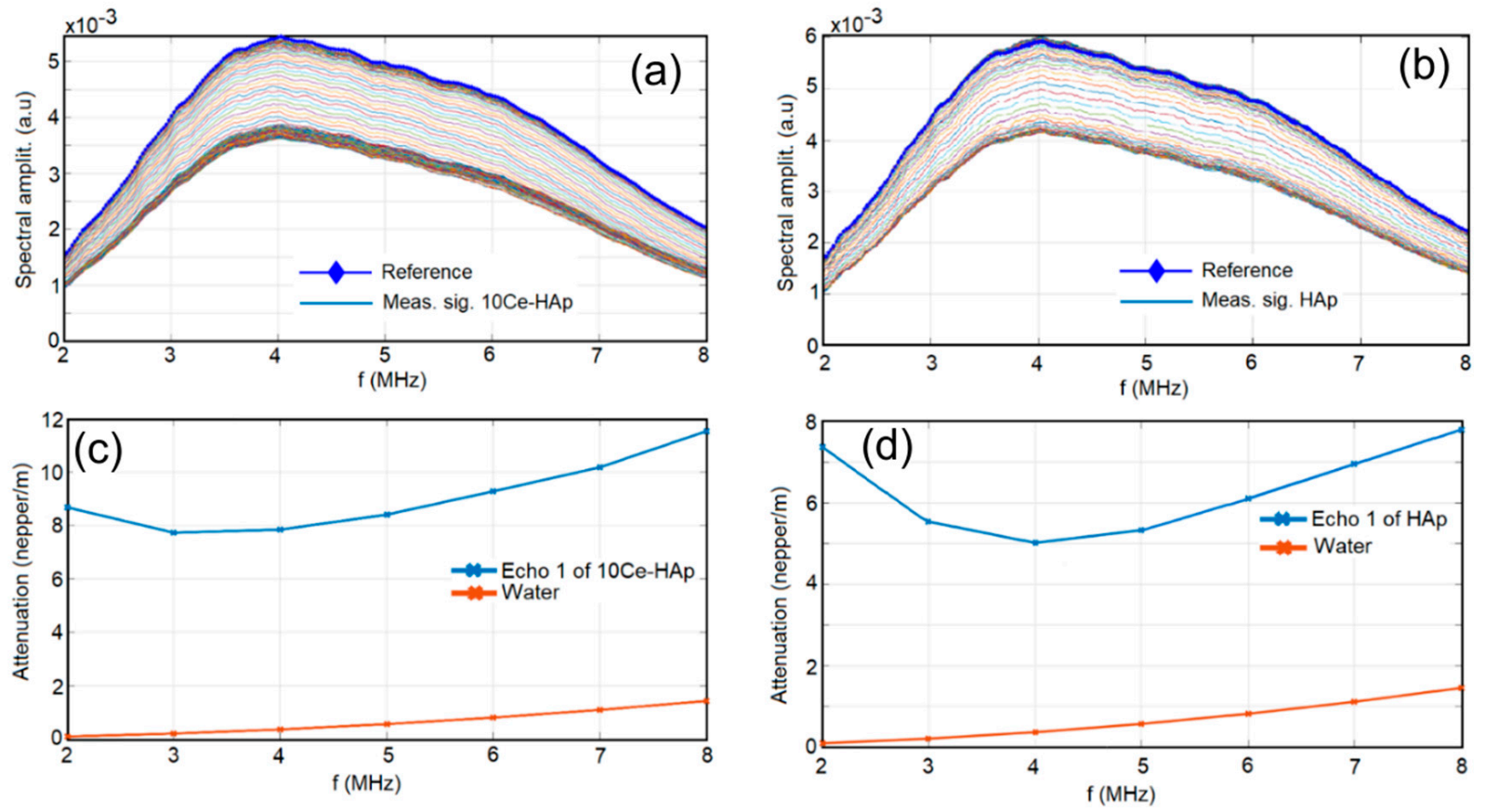

Figure 1. Frequency spectrum of the first transmitted echo of 10Ce-HAp (a) and HAp (c); Attenuation dependency of frequency for 10Ce-HAp (b) and HAp (d). 10Ce-HAp: cerium-doped hydroxyapatite $\left(\mathrm{Ca}_{10-x} \mathrm{Ce}_{x}\left(\mathrm{PO}_{4}\right)_{6}(\mathrm{OH})_{2}\right.$ with $x_{\mathrm{Ce}}=0.1$; Hap: hydroxyapatite.

The stability parameter calculated for the 10Ce-HAp suspension was $s=1.62 \times 10^{-4} \mathrm{~s}^{-1}$, while for HAp, the value of this parameter was $s=6.2 \times 10^{-4} \mathrm{~s}^{-1}$. The value of this parameter relative to the water stability parameter $(s=0)$ shows that the suspension is relatively stable. As 10Ce-HAp suspensions showed better stability (closer to that of double-distilled water), the studies were performed mainly on 10Ce-HAp coatings.

On the other hand, the effect of cerium doping on hydroxyapatite was assessed by a TEM observation. The image shown in Figure 2 shows ellipsoidal nanoparticles with nanometric dimensions (between $10 \pm 1$ and $25 \pm 2 \mathrm{~nm}$ ). As can be seen, the aggregation of the nanoparticles was minimal.

Furthermore, XRD studies provided information on the size of 10Ce-HAp particles (Figure 3a). For these studies, the 10Ce-HAp suspension was centrifuged, and the resulting precipitate was dried under the same conditions as the coatings made $\left(500{ }^{\circ} \mathrm{C}\right)$. The resulting 10Ce-HAp powder was analyzed by X-ray diffraction. The Debye-Scherrer equation [40-43] was used to calculate the average particle size. Particle size and lattice constants were calculated using the diffraction peaks associated with planes (300) and (002) of 10Ce-HAp (Table 1). To highlight the fact that 10Ce-HAp retains the characteristics of pure hydroxyapatite in terms of intensities and peak shifting, we chose diffraction planes (002) and (300). It is known that the most significant differences are observed in the range from $22^{\circ}$ to $35^{\circ}$ [44]. This range $\left(22^{\circ}\right.$ to $\left.35^{\circ}\right)$ is corresponding to the (002), (211), and (300) diffraction planes. These XRD results estimate that the 10Ce-HAp nanoparticles increased preferentially along with the a-axis of its crystal plane, obtaining ellipsoidal nanoparticles. The values of "a" and "c" of 10Ce-HAp were 9.44 and $6.89 \AA$. The values are close to those of pure HAp (9.416 and $6.874 \AA$ ). When cerium ions were incorporated into HAp, a slight increase in the values of the parameters "a" and " $c$ " was observed. These results were in good agreement with previous studies [45]. The results attest to the fact that cerium ions were incorporated into the HAp lattice during synthesis. The results attest to the substitution of $\mathrm{Ca}^{2+}$ with cerium in the HAp lattice during synthesis. The ease of substitution could be assigned to the ionic radii of cerium $\left(0.114 \mathrm{~nm}\right.$ for $\mathrm{Ce}^{3+}$ and $0.097 \mathrm{~nm}$ for $\left.\mathrm{Ce}^{4+}\right)$ that are comparable with ionic radius of $\mathrm{Ca}^{2+}(0.106 \mathrm{~nm})[46,47]$. The XRD results are in agreement with TEM investigation. A slightly larger particle size obtained from TEM 
observations than XRD results could be due to the fact that TEM is able to "see" both the crystal domain and the amorphous domain of a particle. Moreover, XRD studies did not show additional maxima belonging to impurities.

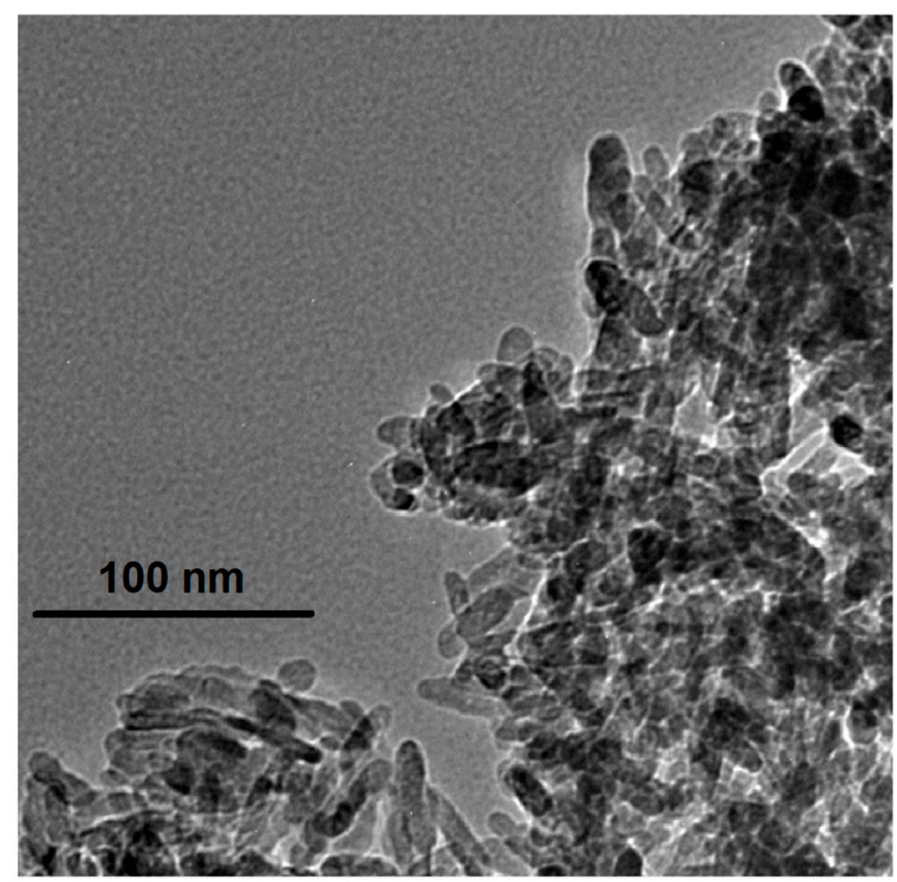

Figure 2. TEM image of 10Ce-HAp.
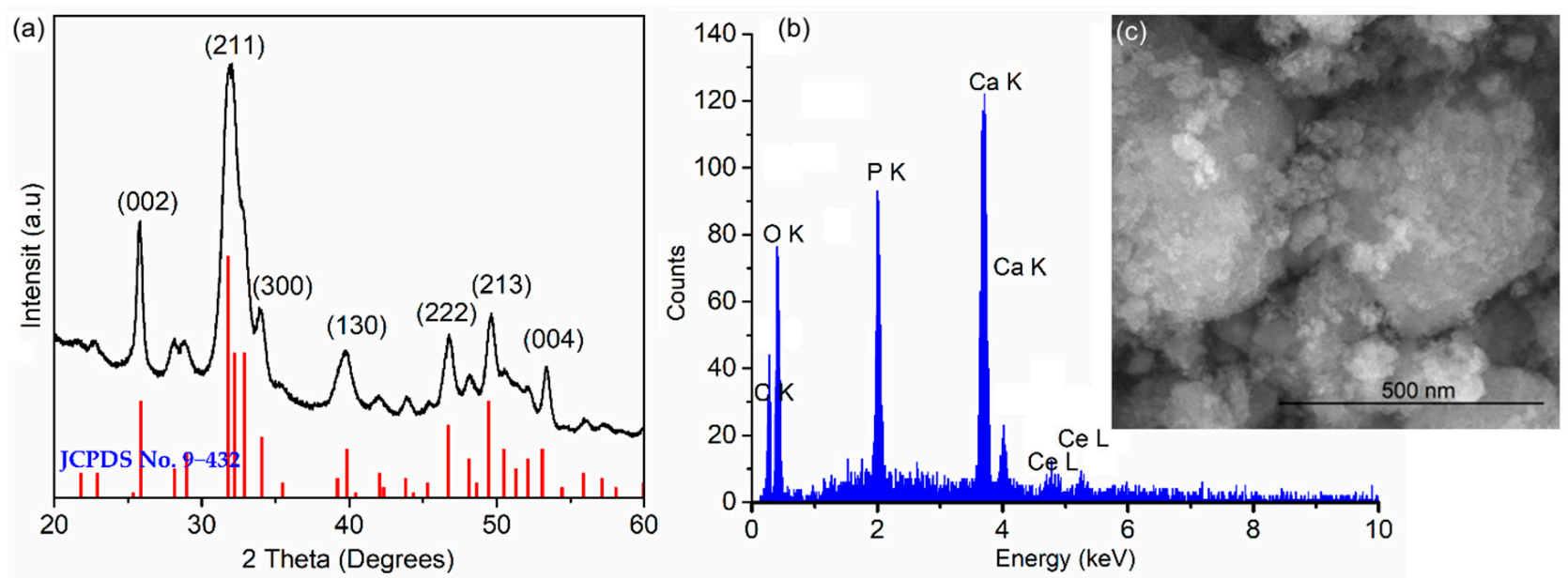

Figure 3. XRD patterns of the 10Ce-HAp in black and of pure hydroxyapatite (JCPDS no. 09-0432) in red (a); energydispersive X-ray spectroscopy (EDS) analysis of 10Ce-HAp (b) and SEM image (c).

Table 1. Lattice constant and crystalline sizes calculated from the XRD patterns of the synthesized 10Ce-HAp suspension.

\begin{tabular}{cccccc}
\hline \multirow{2}{*}{ Sample } & \multicolumn{3}{c}{ Lattice Constant } & \multicolumn{3}{c}{ Crystalline Size } \\
& $\mathbf{a}(\AA)$ & $\mathbf{c}(\AA)$ & $\mathbf{d}_{\mathbf{3 0 0}}(\AA)$ & $\mathbf{d}_{\mathbf{0 0 2}}(\AA)$ & $\mathbf{d}_{\mathbf{0 0 2}}(\AA) / \mathbf{d}_{\mathbf{3 0 0}}(\AA)$ \\
\hline HAp (JCPDS No.9-432) & 9.416 & 6.874 & - & - & - \\
10Ce-HAp & 9.44 & 6.89 & $9.4 \pm 0.5$ & $23.7 \pm 0.8$ & 2.52 \\
\hline
\end{tabular}

The SEM microscopy method was used to investigate the morphology of the 10CeHAp suspension synthesized in order to prepare the coating. A characteristic micrograph 
of the synthesized 10Ce-HAp suspension was exhibited in Figure 3c. The examination of Figure $3 c$ show nanoscale particles according to the results of TEM and XRD studies. The presence of constituent elements of HAp $(\mathrm{Ca}, \mathrm{P}$, and $\mathrm{O})$ as well as the presence of $\mathrm{Ce}$ revealed that the HAp was successfully doped with Ce (Figure 3b).

The surface morphology of the 10Ce-HAp coating was investigated by SEM and AFM techniques. Figure $4 \mathrm{a}, \mathrm{b}$ represents the SEM images of the deposited 10Ce-HAp coating. According to 2D and 3D SEM images, it can be stated that the coating surface was uniform and smooth without cracks or unevenness. The particles have nanometric dimensions in accordance with the SEM results obtained for the 10Ce-HAp suspension. SEM studies of 10Ce-HAp coatings have shown that suspensions with stability coefficient $s=1.62 \times 10^{-4} \mathrm{~s}^{-1}$ can lead to uniform coatings when these are made by the spin coating method. Complementary information regarding the morphology of the 10Ce-HAp coating's surface was achieved by AFM investigations. The AFM 2D surface topography of the 10Ce-HAp coating is depicted in Figure 4c. The results of the AFM studies highlighted that the 10Ce-HAp coating has the morphology of a uniform and homogenous layer. The 2D topography recorded on a surface of $5 \times 5 \mu \mathrm{m}^{2}$ also suggested that the coating is continuous and does not present any visible fissures, cracks, or other impurities on its surface. In addition, the 3D representation obtained with Gwydion software using the 2D topography of the 10Ce-HAp coating also emphasized the presence of a uniform and continuum deposited layer (Figure $4 \mathrm{~d}$ ). The AFM results were in agreement with the SEM studies and suggested that the 10Ce-HAp coating present a uniform and homogenous surface without any discontinuities of impurities. More than that, the roughness parameters of the surface were calculated from the AFM 2D topography. The results have revealed that the $10 \mathrm{Ce}-$ HAp coating's surface presented a roughness average $\left(R_{\mathrm{a}}\right)$ of $46.96 \mathrm{~nm}$ and a root mean square roughness of ( $\left.R_{\mathrm{RMS}}\right)$ of $61.82 \mathrm{~nm}$. The AFM results highlighted that the 10Ce-HAp surface presented a homogenous and uniformly morphology with a diminished roughness.
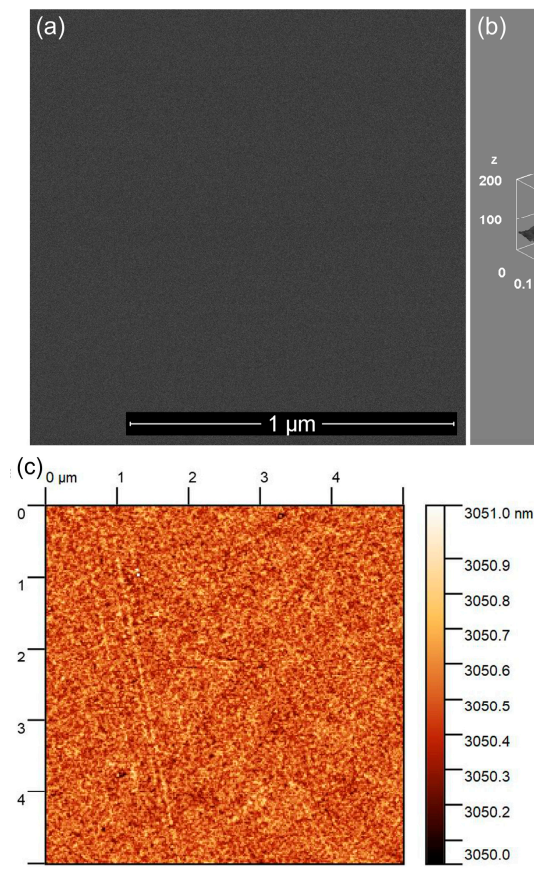

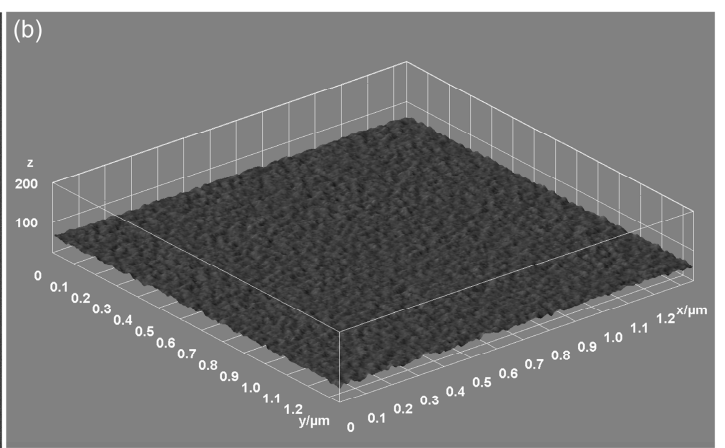

(d)

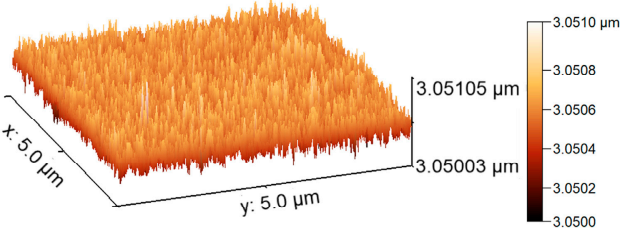

Figure 4. Two-dimensional (2D) (a) and 3D (b) SEM image of 10Ce-HAp coating and 2D atomic force microscopy (AFM) topography of 10Ce-HAp coating (c) and 3D representation of the surface topography of the 10Ce-HAp coating $(\mathbf{d})$.

The SEM/EDS method also allowed elementary quantitative analysis of 10Ce-HAp coatings. Typical EDS patterns highlight distinct peaks at energies that are associated to the $\mathrm{Ca}, \mathrm{O}, \mathrm{P}, \mathrm{Ce}, \mathrm{Si}$, and C elements (Figure 5b). Moreover, during the EDS analysis, the element 
map was scanned (Figure 5a). Following the element map scanning, it was clearly observed that the elements $\mathrm{Ca}, \mathrm{O}, \mathrm{P}$, and Ce were homogeneously dispersed in the analyzed sample.
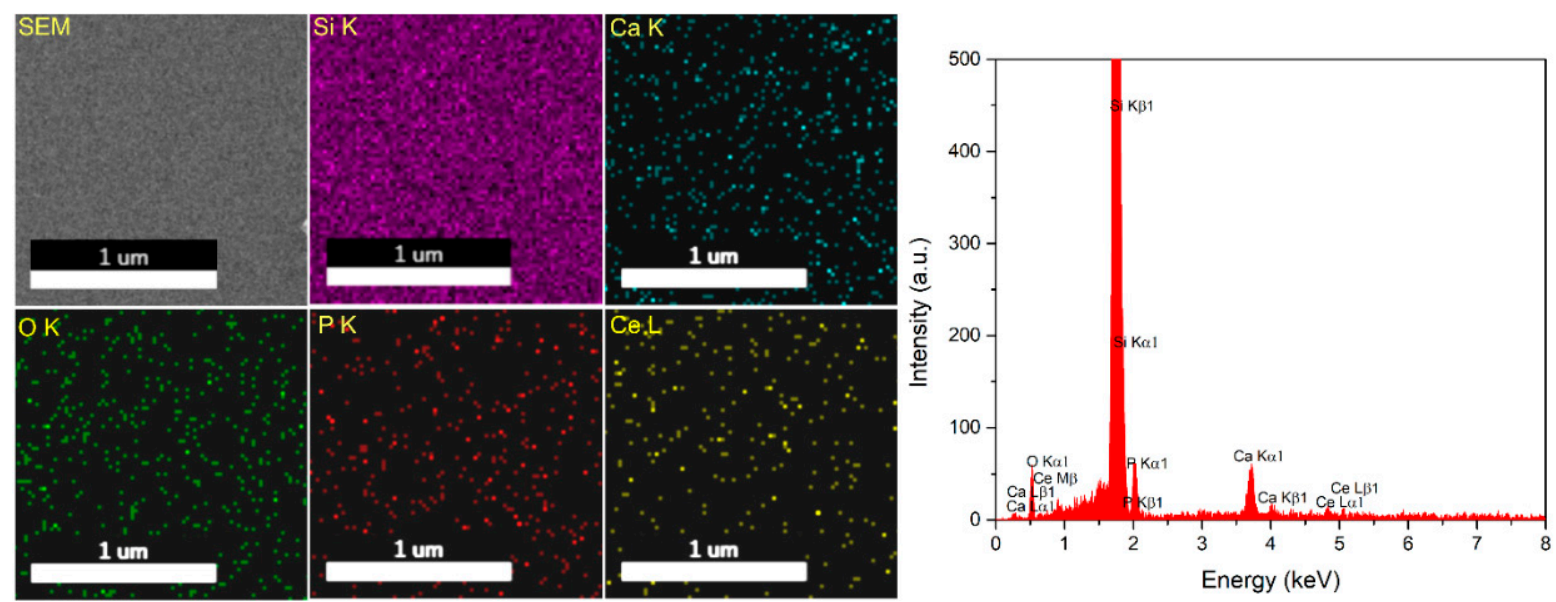

Figure 5. EDS cartography of 10Ce-HAp coating and typical EDS spectrum of 10Ce-HAp coating.

The XPS analysis of 10Ce-HAp were performed to highlight the doping of hydroxyapatite with cerium ions following the synthesis process. Following the XPS studies, the chemical state of the surface was evaluated. As a result of this evaluation, the oxidation state of the cerium ions in the surface of the analyzed sample (10Ce-HAp) was determined. Figure 6a shows both the general XPS spectrum of the 10Ce-HAp sample and the XPS spectrum of Ce (3d) before etching. In the general XPS spectrum of the 10Ce-HAp sample accumulated before etching, the constituent elements of the analyzed sample $(\mathrm{Ce}(3 \mathrm{~d}) \mathrm{Ca}$ (2p), $\mathrm{O}(1 \mathrm{~s})$, and P (2p)) at binding energies of 880-930 eV were identified, 340-350, 351, and $133 \mathrm{eV}$ according to previous studies [48,49]. The signal recorded for C1s was due to the reference carbon (289.5 eV before etching). The XPS spectrum of Ce (3d) of 10Ce-HAp before etching was exposed in Figure $6 \mathrm{~b}$. The contents of $\mathrm{Ce}^{3+}$ and $\mathrm{Ce}^{4+}$ in the sample were estimated from the area under the deconvoluted spectra. In Figure 6b, the upper spectra show the data and total fit to date after the subtraction of a linear background, while the lower spectra revealed $\mathrm{Ce}^{3+}$ by the dashed line and $\mathrm{Ce}^{4+}$ by the dotted line. The percentage of $\mathrm{Ce}^{3+}$ ions on the surface of the $10 \mathrm{Ce}-\mathrm{HAp}$ coating before etching was $86.8 \%$, while the percentage of $\mathrm{Ce}^{4+}$ ions was $13.2 \%$.

The XPS general spectra and XPS spectrum of Ce (3d) of 10Ce-HAp coating after etching were presented in Figure 7. In agreement with previous studies [48], the constituent elements of hydroxyapatite such as $\mathrm{Ca}, \mathrm{P}$, and $\mathrm{O}$ were identified in the XPS spectrum of 10Ce-HAp coating after etching (Figure 7a). The presence of Ce in the XPS general spectra of 10Ce-HAp coating at the BE of 880-920 eV [49] confirmed that the hydroxyapatite doped with Ce was successfully performed (Figure 7a). The analysis of the XPS spectrum of Ce (3d) of the 10Ce-Hap coating after etching from the area under the deconvoluted spectra showed that the percentage of $\mathrm{Ce}^{3+}$ ions on the surface of 10Ce-HAp coating before etching was $52.8 \%$, while the percentage of $\mathrm{Ce}^{4+}$ ions was $47.2 \%$ (Figure $7 \mathrm{~b}$ ). 

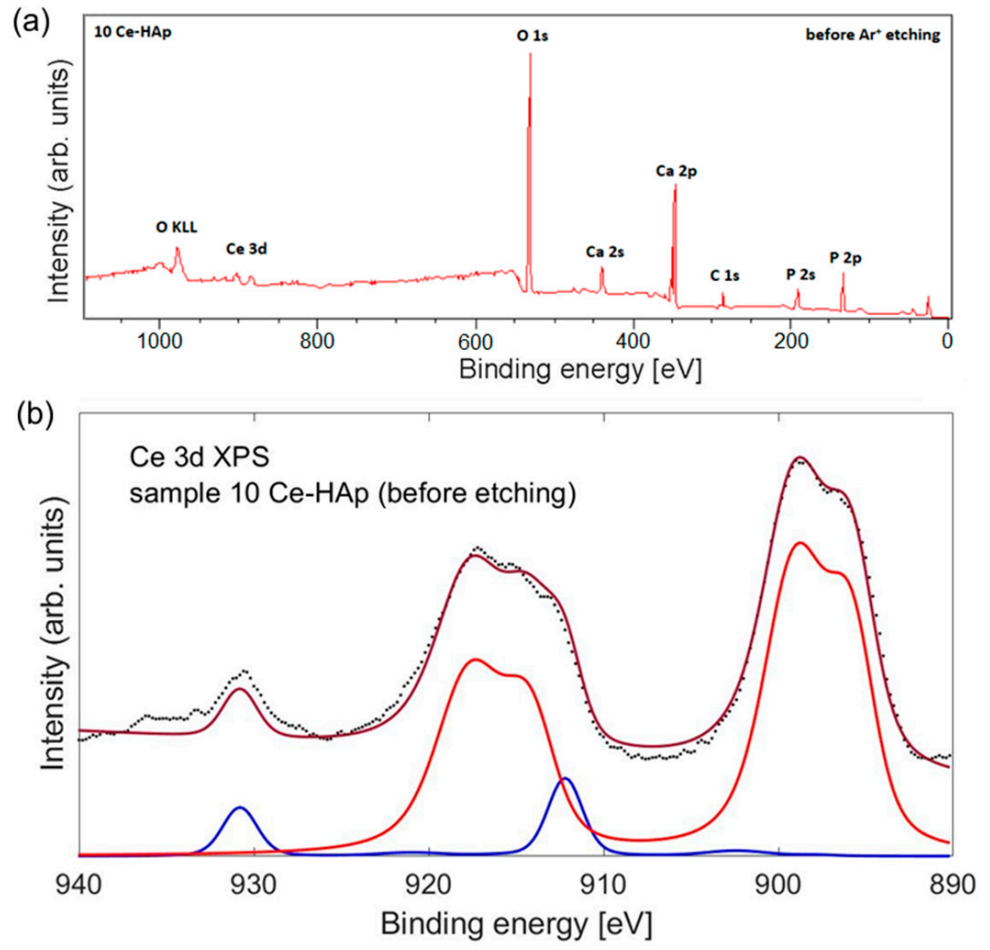

Figure 6. XPS spectra (a) and XPS spectrum of Ce (3d) regions (b) of the 10Ce-HAp coating before etching. Upper spectra: Data (points) and total fit (brown line) to date after subtraction of a linear background; Lower spectra: Dashed line represents $\mathrm{Ce}^{3+}$ (red line) and dotted line represents $\mathrm{Ce}^{4+}$ (blue line).

(a)

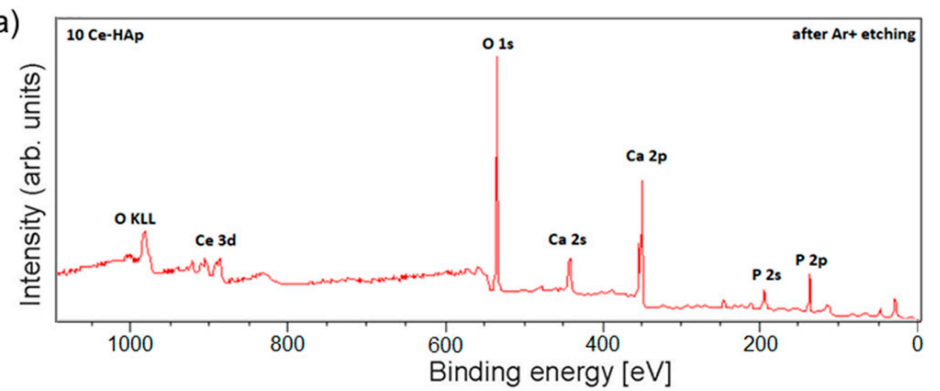

(b)

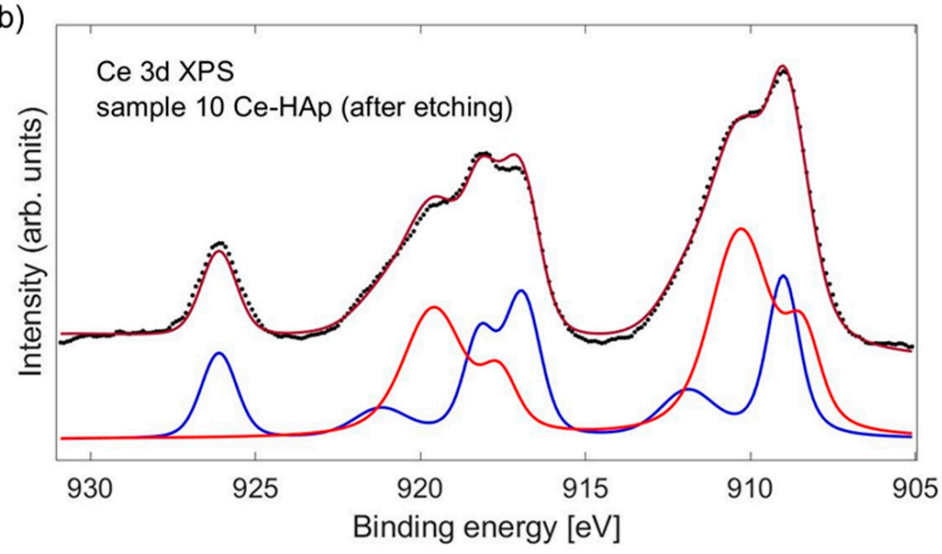

Figure 7. XPS spectra (a) and XPS spectrum of Ce (3d) regions (b) of the 10Ce-HAp coating after etching. Upper spectra: Data (points) and total fit (brown line) to date after subtraction of a linear background; Lower spectra: The dashed line represents $\mathrm{Ce}^{3+}$ (red line) and the dotted line represents $\mathrm{Ce}^{4+}$ (blue line). 
The XPS analysis technique used in the analysis of the surface of the 10Ce-HAp sample before and after etching confirmed the oxidation state of the Ce ions incorporated in the hydroxyapatite that were involved in the replacement of the $\mathrm{Ca}^{2+}$ sites in the hydroxyapatite structure. The formation of $\mathrm{CeO}_{2}$ at the surface of the coating could have been possible as a result of the thermic treatment and/or deposition process $[24,50]$. As it could be observed, after engraving, the percentage of $\mathrm{Ce}^{4+}$ was significantly higher $(47.2 \%$ compared to $13.2 \%$ before engraving). This result shows that the technique of obtaining coatings plays a very important role in the oxidation process of $\mathrm{Ce}^{3+}$ in $\mathrm{Ce}^{4+}$. In our previous study [24], we showed that in the case of 5Ce-HAp coatings generated in plasma by radio frequency magnetron sputtering discharge in Ar gas flow in a single run, the percentage of $\mathrm{Ce}^{3+}$ and $\mathrm{Ce}^{4+}$ ions calculated for 5Ce-HAp layer before and after etching varied by $\approx 1 \%$.

$$
\beta=(0.94 \cdot \lambda) /(\mathrm{D} \cos \theta)
$$

According to recent studies that have shown the enormous potential of glow discharge optical emission spectroscopy (GDOES) for the depth profiling of extremely thin films, conducting or non-conducting with a thickness of less than $10 \mathrm{~nm}$ [51], in this study, the GDOES method was used for depth profiling of the 10Ce-HAp coating on an Si substrate. By the GDOES method, it was possible to observe the distribution of the components of the 10Ce-HAp coating from the surface to the substrate interface. Figure 8 presents the GDOES elemental depth profiles of the 10Ce-HAp coating on Si substrate. The coating consisted of hydrogen, oxygen, phosphorus, calcium, and cerium. By the GDOES method, it was possible to observe the distribution of the components of the 10Ce-HAp coating from the surface to the substrate interface. Figure 8 presents the GDOES elemental depth profiles of 10Ce-HAp coating on silicium substrate. The coating consisted of hydrogen, oxygen, phosphorus, calcium, and cerium. The low-intensity Si component comes from the substrate of the sample. It observed a similar comportment for the depth profiles of $\mathrm{Ca}, \mathrm{P}, \mathrm{O}$, and Ce. The thin film thickness was estimated to be about $190 \mathrm{~nm}$. The thin film thickness was evaluated using profilometry (measuring the depth of the glow discharge (GD) crater). The average rate of ablation was around $2 \mathrm{~s} / \mathrm{min}$.

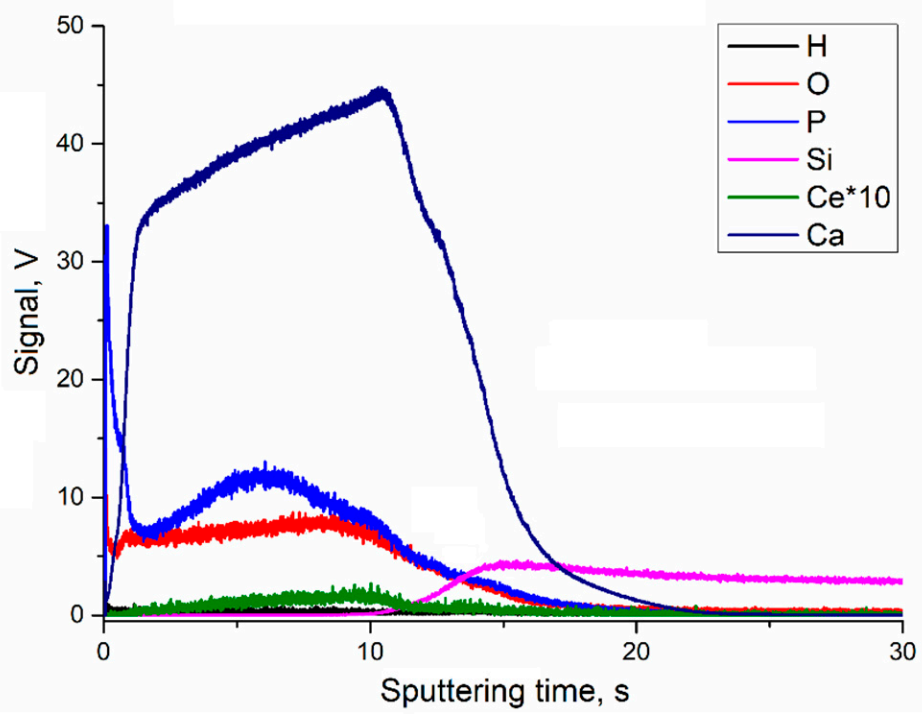

Figure 8. Compositional depth profiles of the 10Ce-HAp coating obtained by glow discharge optical emission spectroscopy (GDOES).

Recently, due to the continuous outbreaks of drug-resistant microorganisms, a great interest was given to the development of novel materials with antimicrobial properties for the fabrication of biocompatible coatings with antimicrobial properties for biomedical 
applications. One of the most encountered microorganisms responsible for pre and postoperatory infections in hospitals worldwide is Candida albicans.

The antifungal properties of the HAp and 10Ce-HAp suspensions and coatings were assessed using Candida albicans ATCC 10,231 strain. The effects of the HAp and 10CeHAp suspensions and coatings on the Candida albicans ATCC 10.231 fungal cells have been investigated at three different time intervals. For this purpose, HAp and 10Ce-HAp suspensions and coatings were incubated with microbial suspensions, and the number of CFU / $\mathrm{mL}$ was determined for each of the contacts after 24,48 , and $72 \mathrm{~h}$. The standard inoculum of a known concentration of $5 \times 10^{6} \mathrm{CFU} / \mathrm{mL}$ was used as control. The results of the quantitative assays depicted in Figure 9 revealed that both 10Ce-HAp suspensions and coatings had a strong inhibitory effect on the development of $C$. albicans fungal cells even after $24 \mathrm{~h}$ of incubation. Furthermore, the results demonstrated that the inhibitory effect of the suspensions as well as the coatings against the development and proliferation of the fungal cells was augmented by the incubation time. In addition, the data also indicated that the 10Ce-HAp suspensions had a fungicidal effect against the C. albicans cells after $72 \mathrm{~h}$ of incubation. In addition, the results of the antifungal assays performed on HAp suspensions and coatings revealed that HAp suspensions and HAp coatings did not inhibit the growth of the $C$. albicans fungal cells. More than that, the results suggested that the presence of the HAp suspensions and coatings have aided the development of the fungal cells and supported their proliferation for all tested time intervals. These results are also supported by the previous reported studies regarded the antimicrobial properties of hydroxyapatite and hydroxyapatite coatings $[24,26,28]$. The statistical analysis of the data was performed using the Student $t$-test, and the values $p, p \leq 0.05$, were accepted as statistically significant.

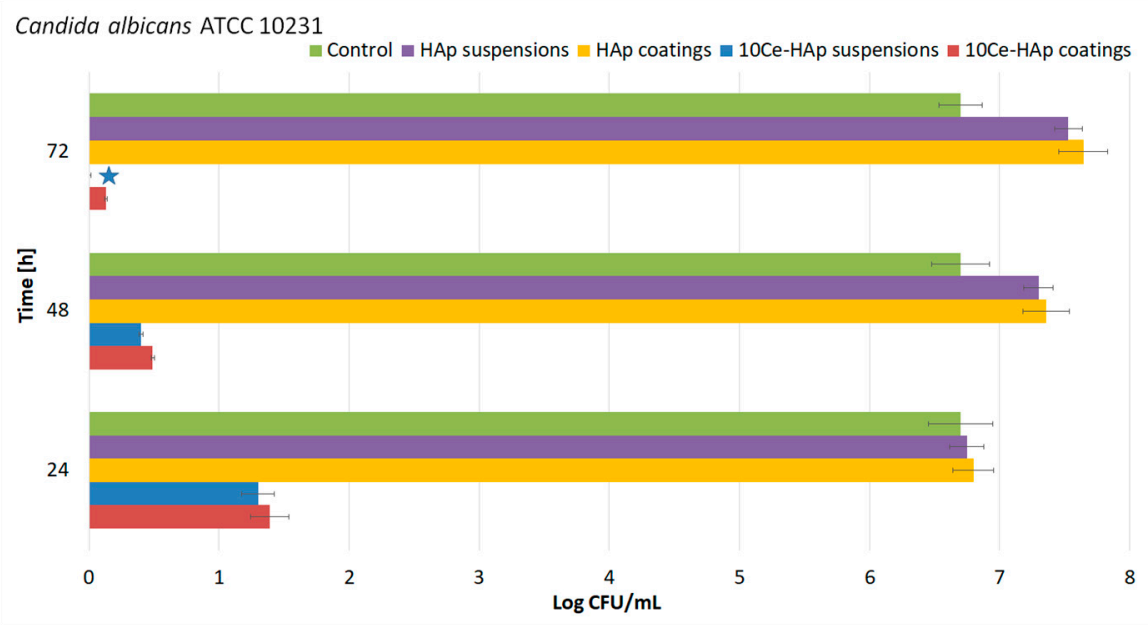

Figure 9. The graphical representation of the Log colony-forming units (CFU)/mL as a function of time of exposure to HAp and 10Ce-HAp suspensions and coatings at different time intervals. The results are presented as means \pm standard error of the mean of two independent experiments. The data were statistically analyzed by using a t-test, $p \leq 0.05$ was accepted as statistically significant.

These results are in good agreement with previous reported studies regarding the antifungal properties of cerium-doped hydroxyapatite nanoparticles and suspensions [18,24,52-58]. The antifungal assay demonstrated that the efficiency of 10Ce-HAp suspensions was greater than the efficiency of 10Ce-HAp coatings in the inhibition of the C. albicans fungal cells development. Moreover, the data also highlighted that there is a direct correlation between the incubation time and the antifungal properties of both 10Ce-HAp suspensions and coatings. Due to the fact that the HAp suspensions and coatings did not present any inhibitory effect against the $C$. albicans cells, the antifungal properties exhibited by the 10Ce-HAp suspensions and coatings could be attributed to the presence of cerium ions from the hydroxyapatite lattice, and the correlation between the antifungal efficiency and 
incubation time could be explained due to the gradual release of cerium ions from the HAp lattice. The antimicrobial mechanism of the cerium ions has been reported in the literature due to their interaction with the fungal cell membrane, which leads to its structural damage and to the cell's death $[57,58]$.

Qualitative assays regarding the adhesion and proliferation of $C$. albicans fungal cells on the surface of 10Ce-HAp coatings were also performed using SEM and CLSM studies. The adhesion and proliferation of the fungal cells on the HAp and 10Ce-HAp surface were investigated at three different time intervals $(24,48$, and $72 \mathrm{~h})$. The images obtained by SEM visualization of the C. albicans fungal cells adhered on the surface of HAp and 10Ce-HAp coatings after 24, 48, and $72 \mathrm{~h}$ of incubation are depicted in Figure 10a-c,g-i. The SEM images revealed that the morphology of the fungal cells adhered on the HAp and 10Ce-HAp coatings was characteristic to that of the $C$. albicans cells with round-to-oval cell shape and sizes between 2.80 and $4.84 \mu \mathrm{m}$. The SEM visualization has shown that the 10Ce-HAp coatings have inhibited the $C$. albicans cell proliferation even after $24 \mathrm{~h}$ of incubation. Moreover, the SEM images emphasized that on the surface of the coatings exposed to C. albicans fungal microbial suspensions, the remaining adhered fungal cells are isolated and also that there was no indication of hyphal formation, which is a proof of the beginning of biofilm formation. These results could lead to the premises that the coatings might be effective in inhibiting the biofilm formation knowing that a biofilm is an aggregate of bacteria held together by an extracellular polymeric substance matrix.

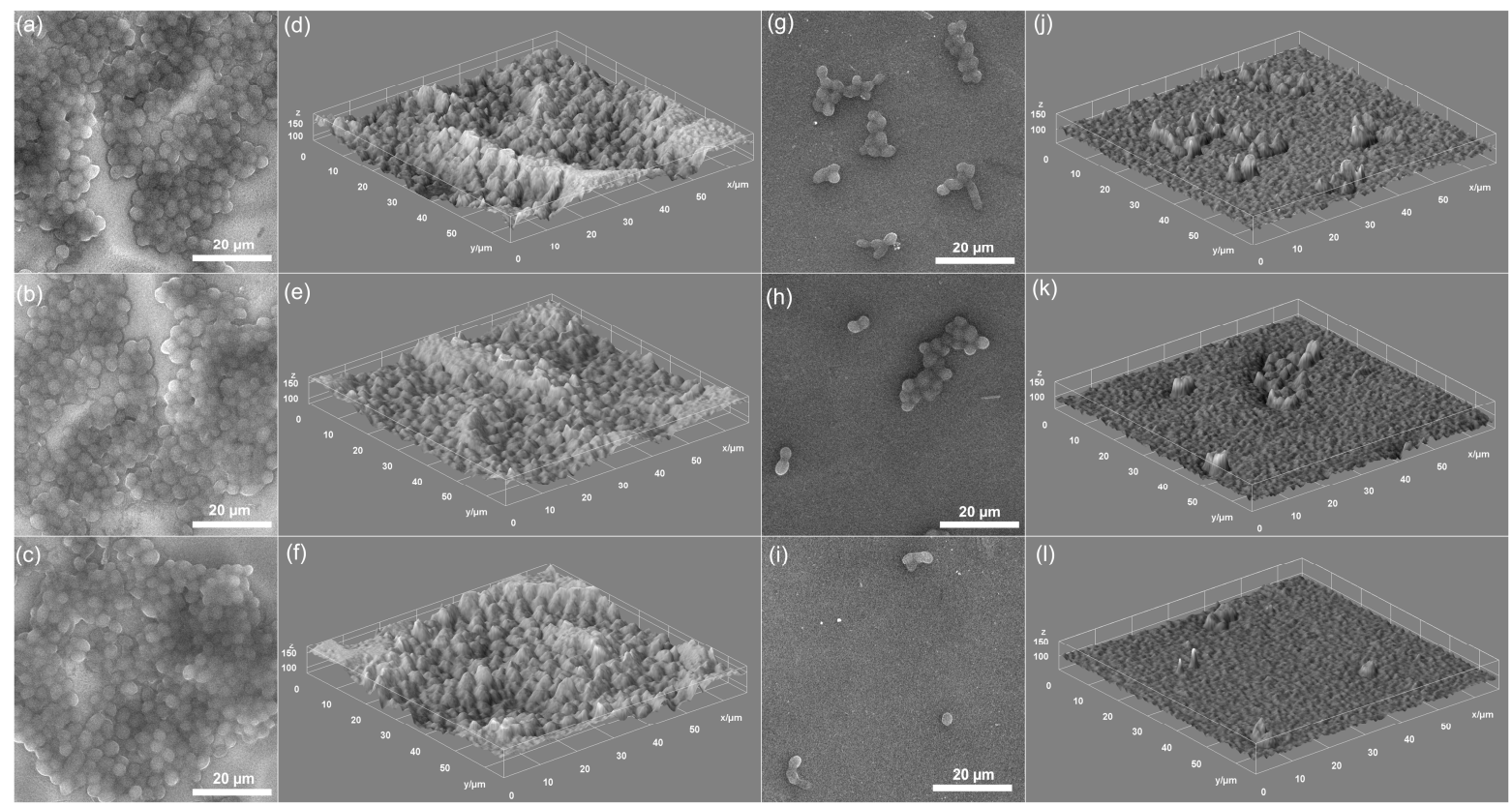

Figure 10. Two-dimensional (2D) SEM images and 3D representation of Candida albicans American Type Culture Collection (ATCC) 10231 cell development on HAp (a-f) and 10Ce-HAp (g-1) coatings at different time intervals of incubation $24 \mathrm{~h}$ $(\mathbf{a}, \mathbf{d}, \mathbf{g}, \mathbf{j}) 48 \mathrm{~h}(\mathbf{b}, \mathbf{e}, \mathbf{h}, \mathbf{k})$, and $72 \mathrm{~h}(\mathbf{c}, \mathbf{f}, \mathbf{i}, \mathbf{l})$.

Furthermore, the SEM visualization has evidenced that the 10Ce-HAp coatings exhibited strong antifungal effects, and that after $72 \mathrm{~h}$ of incubation time, it almost completely eradicated the $C$. albicans fungal cell and also that the antifungal properties are correlated with the incubation time. These results are in agreement with the quantitative assay results. More than that, the SEM studies have evidenced that the number of fungal cells adhered to the 10Ce-HAp surface has been substantially lowered from 24 to $48 \mathrm{~h}$ of incubation. In addition, the 3D representation of the SEM images representing the $C$. albicans fungal cells attached on the HAp and 10Ce-HAp surface are also depicted in Figure 10d-f,j-l. The 3D depiction of the SEM images was realized with the aid of Image J software (Image J 1.51j8). 
Complementary information about the adhesion and proliferation of the $C$. albicans fungal cells on the surface of HAp and 10Ce-HAp coatings was also obtained by CLSM investigation. The results of the CLSM visualization are presented in Figure 11.
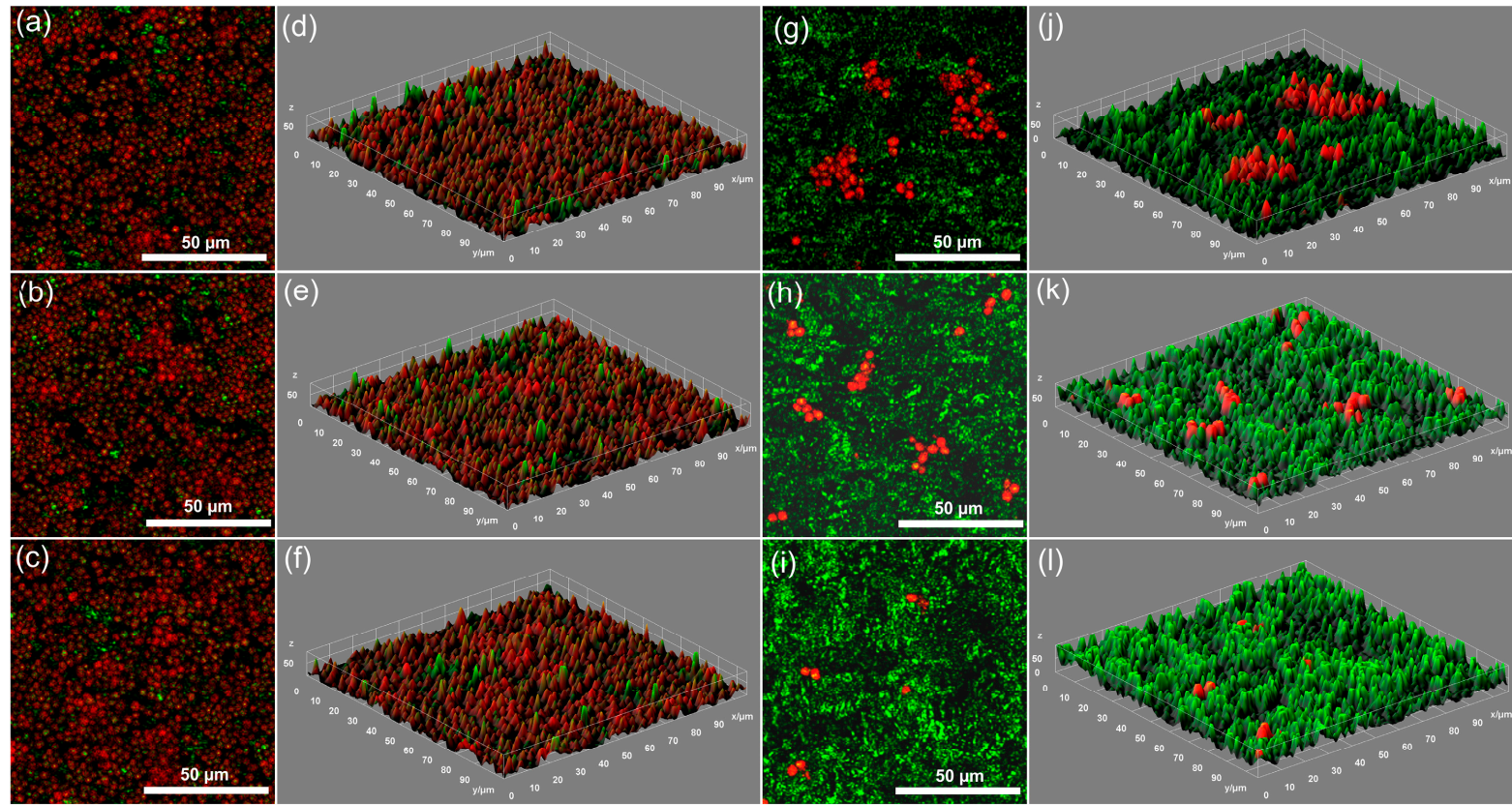

Figure 11. Two-dimensional (2D) confocal laser scanning microscopy (CLSM) images and 3D representation of Candida albicans ATCC 10,231 adhesion on HAp (a-f) and 10Ce-HAp (g-1) coatings at different time intervals of incubation $24 \mathrm{~h}$ $(\mathbf{a}, \mathbf{d}, \mathbf{g}, \mathbf{j}), 48 \mathrm{~h}(\mathbf{b}, \mathbf{e}, \mathbf{h}, \mathbf{k})$, and $72 \mathrm{~h}(\mathbf{c}, \mathbf{f}, \mathbf{i}, \mathbf{l})$.

The CLSM 2D images of the fungal cells attached on the HAp and 10Ce-HAp coating's surface after 24, 48, and $72 \mathrm{~h}$ of incubation are depicted in Figure 11a-c,g-i. The results of the CLSM visualization revealed that the fungal cells attached to the 10Ce-HAp surface have the morphology of regular ovoid "yeast" cells with sizes ranging from 2.45 to $4.89 \mu \mathrm{m}$. The CLSM images highlighted that the 10Ce-HAp inhibited the C. albicans cells development and attachment on its surface, and that did not allow the formation of biofilm. The CLSM studies were performed using propidium iodide for the staining of the fungal cells. The results of the CLSM investigation revealed that the 10Ce-HAp coatings inhibited the development and adherence of the fungal cells on its surface after 24 of incubation. In addition, the data also suggested that the fungal cells have been significantly reduced after $48 \mathrm{~h}$ of incubation. Moreover, the visualization revealed that the antifungal effects were stronger after $72 \mathrm{~h}$ of incubation. After $72 \mathrm{~h}$ of incubation, the results suggested that the fungal cells have been almost eliminated. Furthermore, the CLSM visualization of the fungal cells adhered on the HAp coatings suggested that the HAp presented no antifungal effects and that it helped the development and adhesion of the $C$. albicans fungal cells on the coating's surface. The CLSM images depicted in Figure 11 highlighted that the 10Ce-HAp coatings were effective in inhibiting the adherence and proliferation of $C$. albicans fungal cells compared to HAp coatings. More than that, the CLSM investigation showed that the few adhered C. albicans cells did not undergo transformation into their filamentous form, hence demonstrating that $C$. albicans were unable to evolve into their biofilm phenotype on the 10Ce-HAp surfaces [59]. These results are in good agreement with SEM visualization as well as the results of the quantitative antifungal assay and with previously reported studies regarding the antifungal properties of composite layers [60,61].

In addition, the $3 \mathrm{D}$ reconstruction of the CLSM images of $C$. albicans fungal cells that were attached on the surface of HAp and 10Ce-HAp coatings after different time intervals $(24,48$, and $72 \mathrm{~h})$ are also depicted in Figure $11 \mathrm{~d}-\mathrm{f}, \mathrm{j}-\mathrm{l}$. The 3D representation of the structure, morphology, and spatial distribution of the fungal cells were analyzed using Image J 
software [29]. The 3D representation images from Figure $11 \mathrm{~d}-\mathrm{f}, \mathrm{j}-1$ presents the spatial distribution of $C$. albicans cells (red) along horizontal (coverage) and the vertical (thickness) distributions on the HAp and 10Ce-HAp coating's surface. The CLSM investigations emphasized that the development of $C$. albicans fungal cells was strongly inhibited by the 10Ce-HAp coatings.

During the years, both bacteria and fungi have continued to evolve and develop new ways in order to adapt to new environments and to survive against various effects of antimicrobials [62]. Studies have shown that bacteria and fungi developed resistance mechanisms using their own DNA. Usually, the genes responsible for the resistance are found within plasmids, which are small pieces of DNA that could be shared and offer resistance to other microorganism [63]. Nonetheless, the structure of the bacteria and fungi are different; thus, there are various mechanisms that are responsible for their resistance to conventional drugs, and also during the year, researchers have investigated alternatives solutions to the use of conventional antimicrobial agents. The most important components of bacterial cells are the cell wall and membranes, which protect them from the external factors. Several studies have reported that often, some nanoparticles exhibited greater antibacterial activity against Gram-positive bacteria than against Gram-negative bacteria. These effects have been attributed to the fact that the cell wall of Gram-negative bacteria is composed of lipopolysaccharide (LPS), lipoproteins, and phospholipids, while the cell wall of Gram-positive bacteria is mainly composed of a thin layer of peptidoglycan and teichoic acid. Therefore, the structure of Gram-positive bacteria allows foreign molecules to penetrate, causing damage to the cell membrane and inevitably leading to the cell's death. In contrast, the Gram-negative bacteria structure allows the entrance of only macromolecules, making it more difficult for the cell membrane to be penetrated by foreign agents. On the other hand, fungi are eukaryotes and have a more complex cellular organization than the prokaryote Gram-positive and Gram-negative bacterial cells. The fungal cells walls are built from complex polysaccharides layers, which are called chitin and glucans, which confers them structural strength [64-68]. Several mechanisms such as interference with cell wall synthesis, the inhibition of protein synthesis and of a metabolic pathway, the interference with nucleic acid, and the disruption of bacterial membrane structure, by which nanoparticles affects bacterial cells have been proposed, but all the undergone studies have concluded that these mechanism are dependent on the components and structure of the bacterial cell. Moreover, the physicochemical properties of nanoparticles have also a significant role in their antibacterial activity. In addition, external factors such as the environmental conditions, the type of bacterial strain, and the incubation time could also influence the antibacterial effects of nanoparticles [63-71]. Even though there are several studies regarding the effects of different types of nanoparticles against bacterial cells, there are only a few studies that have addressed the influence of the roughness [71-74]. While there are studies regarding Candida resistance in order to prevent biofilm formation, a smaller attention was directed toward understanding whether the modifications of surface topography can affect $C$. albicans biofilm development. A handful of studies have reported that $C$. albicans cell development and adherence could be influenced by the biomaterial surface $[75,76]$. It has been reported that $C$. albicans cells could adhere and form biofilm on surfaces having an average surface roughness $\left(S_{\mathrm{a}}\right)$ between 400 and $600 \mathrm{~nm}$ in just $48 \mathrm{~h}$ of incubation [77]. More than that, another study conducted by Mahayana et al. [78] reported that the $C$. albicans cell density on a surface denture resin having a $S_{\text {a value of } 3200 \mathrm{~nm} \text { had }}$ increased considerably compared to a surface having a $S_{a}$ value of $60 \mathrm{~nm}$. Nonetheless, due to scarce studies conducted by now, there has not been yet reached a consensus regarding the influence of the surface roughness in the development and adherence of $C$. albicans fungal cells. The results obtained by Le et al. [79] in their study regarding "nanoscale surface roughness influences Candida albicans biofilm formation" have evidenced that that surface topography could influence the adherence of $C$. albicans cells and also, the results suggested that a specific surface architecture could be used to repel C. albicans attachment, therefore preventing the biofilm formation. Their study revealed that surfaces having an 
average surface roughness $S_{\text {a }}$ less than $20 \mathrm{~nm}$, combined with a certain topography, was highly effective at preventing the attachment of $C$. albicans. Despite the several studies that exist regarding the responsible mechanism for the antimicrobial properties of certain materials and surfaces, the data are still incomplete, and there is a need for further complex investigation in order to better understand these phenomena. Various studies reported different results for numerous materials and surfaces. There is still a consensus regarding the fact that the antimicrobial properties are influenced by the physicochemical properties of the samples, the bacterial or fungal strain, and also various external parameters. Furthermore, in the case of coatings, the antimicrobial activity has been also correlated with the synergistic connection between the chemical constituents of the coating and substrate. Our results suggested that the antifungal properties of both 10Ce-HAp suspensions and $10 \mathrm{Ce}-\mathrm{HAp}$ coatings were attributed to the presence of cerium ions in the lattice of the hydroxyapatite. Furthermore, the results are in good agreement with previously reported studies by both Lin et al. [18] and Ciobanu et al. [52] regarding the antimicrobial properties of cerium-doped hydroxyapatite, which concluded that the antimicrobial properties of the samples were influenced by several factors such as stability, grain size, nanoparticle shape, surface roughness, time of incubation, and also by the cerium ion concentration from the hydroxyapatite lattice. More than that, the coatings had a roughness average $\left(R_{\mathrm{a}}\right)$ of $46.96 \mathrm{~nm}$, which according to the literature could also be a factor in inhibiting the development and adherence of $C$. albicans fungal cells on its surface. In addition, the mechanisms involved in the antifungal properties of the cerium ions could be attributed to their ability of producing reactive oxygen species (ROS), or inflicting direct damage to the cell membrane leading to the cell's death. This study showed that the stability of the suspensions is strongly influenced by the method of synthesis. The stability parameters for the 10Ce-HAp and HAp suspensions were lower than for the $5 \mathrm{Ce}-\mathrm{HAp}\left(\mathrm{Ca}_{10-x} \mathrm{Ce}_{x}\left(\mathrm{PO}_{4}\right)_{6}(\mathrm{OH})_{2}\right.$ with $x_{\mathrm{Ce}}=0.05$ ) suspensions presented in a previous study [24]. Both the stirring time and the temperature at which the obtained suspension was stirred seem to play an important role in the stability of the suspensions. Suspensions of 10Ce-HAp nanoparticles with a stability parameter $s=1.62 \times 10^{-4} \mathrm{~s}^{-1}$ were ideal for obtaining uniform coatings without defects. These studies have allowed us to highlight some synthesis conditions that must be taken into account in order to obtain stable suspensions in order to have uniform layers.

The results obtained by the quantitative and qualitative antifungal assays demonstrated that the 10Ce-HAp coatings exhibited good antifungal properties and that could be considered for the development of newly antifungal coatings for medical devices.

\section{Conclusions}

The 10Ce-HAp coatings were prepared by the spin coating technique from stable 10Ce-HAp suspensions for the first time. XRD, TEM, and SEM investigations revealed that the 10Ce-HAp particles exhibited nanometric sizes with ellipsoidal morphology. The EDS studies revealed the elemental composition of the 10Ce-HAp solutions and coatings. The data obtained by SEM and AFM investigations demonstrated that the surface of 10Ce-HAp coatings was homogenous and did not present any fissures or discontinuities. Ca, P, O, Ce, and Si were identified in the XPS general spectra of the 10Ce-HAp coating before and after etching. The distribution of the components of the 10Ce-HAp coating from the surface to the Si substrate interface was observed by the GDOES method. The results were in agreement with EDS and XPS analysis. The elemental mapping analysis showed that the $\mathrm{Ca}, \mathrm{P}, \mathrm{O}$, and $\mathrm{Ce}$ chemical elements were evenly distributed in the sample. Studies have shown that particle suspension with a stability parameter $s=62 \times 10^{-4} \mathrm{~s}^{-1}$ could be used to achieve uniform coatings without cracks and unevenness. The quantitative antifungal assays revealed that both $10 \mathrm{Ce}-\mathrm{HAp}$ suspensions and coatings were effective in inhibiting the $C$. albicans fungal cell development for all tested time intervals compared to the HAp suspensions and coatings. Moreover, the data emphasized that the inhibitory effect of the samples increased with the increase of the incubation period. The SEM and CLSM visualization have also confirmed the results of the antifungal quantitative assays and 
suggested that the 10Ce-HAp coatings inhibited the fungal cell development, proliferation, and adherence. In addition, the results have also lead to the premises that 10Ce-HAp did not allow the C. albicans biofilm formation. The results lead to the conclusion that the 10Ce-HAp suspensions and coatings could be effectively used in the development of novel antifungal devices for biomedical applications.

Author Contributions: Conceptualization, D.P., P.C., and K.R.; methodology, D.P., M.V.P., P.C., S.G., S.R., S.L.I., M.M.-H., and K.R.; software, M.V.P., S.L.I. and D.P.; validation, D.P., M.V.P., P.C., S.G., S.R., S.L.I., M.M.-H., and K.R.; formal analysis, D.P., M.V.P., P.C., S.G., S.R., S.L.I., M.M.-H., and K.R.; investigation, D.P., M.V.P., P.C., S.G., S.R., S.L.I., M.M.-H., and K.R.; resources, D.P., M.M-H., P.C., K.R., and S.R.; data curation, D.P., M.V.P., P.C., S.G., S.R., S.L.I., M.M.-H., and K.R.; writing-original draft preparation, D.P., M.V.P., S.L.I., and K.R.; writing-review and editing, D.P., M.V.P., P.C., S.G., S.R., S.L.I., M.M.-H., and K.R.; visualization, D.P., M.V.P., P.C., S.G., S.R., S.L.I., M.M-H., and K.R.; supervision, D.P., P.C., M.M.-H., and K.R.; project administration, D.P.; funding acquisition, D.P. and S.L.I. All authors have read and agreed to the published version of the manuscript.

Funding: This research was partially funded by the Romanian Ministry of Research and Innovation with the grant number and project number PN-III-P1-1.2-PCCDI-2017-0629/contract no. 43PCCDI/2018.

Institutional Review Board Statement: Not applicable.

Informed Consent Statement: Not applicable.

Data Availability Statement: Data is available on demand from the corresponding author.

Acknowledgments: We thank R. Hristu and G. Stanciu from the University Politechnica of Bucharest for assistance in CLSM data acquisition.

Conflicts of Interest: The authors declare no conflict of interest.

\section{References}

1. Siegel, J.D.; Rhinehart, E.; Jackson, M.; Chiarello, L. Management of Multidrug-Resistant Organisms in Healthcare Settings; Centers for Disease Control and Prevention: Atlanta, GA, USA, 2006. Available online: https://www.cdc.gov/infectioncontrol/guidelines/ mdro/index.html (accessed on 20 March 2021).

2. Sievert, D.M.; Ricks, P.; Edwards, J.R.; Schneider, A.; Patel, J.; Srinivasan, A.; Kallen, A.; Limbago, B.; Fridkin, S. Antimicrobial resistant pathogens associated with healthcare associated infections: Summary of data reported to the national healthcare safety network at the centers for disease control and prevention, 2009-2010. Infect. Control Hosp. Epidemiol. 2013, 34, 1-14. [CrossRef] [PubMed]

3. Gow, N.A.R. Microbe Profile: Candida albicans: A shape-changing, opportunistic pathogenic fungus of humans. Microbiology 2017, 163, 1145-1147. [CrossRef] [PubMed]

4. James, S.A.; Roberts, I.N.; Elliston, A.; Bond, C.J.; Ludwig, J.M.; Dicks, J.; Bensasson, D. Diverse Lineages of Candida albicans Live on Old Oaks. Genetics 2019, 211, 277-288. [CrossRef]

5. Odds, F.C. Candida and Candidosis: A Review and Bibliography, 2nd ed.; Bailliere Tindall: Philadelphia, PA, USA; London, UK, 1988; ISBN 978-0702012655.

6. Kurtzman, C.P.; Fell, J.W. The Yeasts, A Taxonomic Study, 4th ed.; Elsevier: Amsterdam, The Netherlands, 1998; ISBN 978-0444813121.

7. Lim, C.S.; Rosli, R.; Seow, H.F.; Chong, P.P. Candida and invasive candidiasis: Back to basics. Eur. J. Clin. Microbiol. Infect. Dis. 2012, 31, 21-31. [CrossRef] [PubMed]

8. Zhang, L.; Zhou, S.; Pan, A.; Li, J.; Liu, B. Surveillance of antifungal susceptibilities in clinical isolates of Candida species at 36 hospitals in China from 2009 to 2013. Int. J. Infect. Dis. 2015, 33, 1-4. [CrossRef] [PubMed]

9. Pelletier, D.A.; Suresh, A.K.; Holton, G.A.; McKeown, C.K.; Wang, W.; Gu, B.; Mortensen, N.P.; Allison, D.P.; Joy, D.C.; Allison, M.R.; et al. Effects of engineered cerium oxide nanoparticles on bacterial growth and viability. Appl. Environ. Microbiol. 2010, 76, 7981-7989. [CrossRef] [PubMed]

10. Yang, X.; Yang, J.; Wang, L.; Ran, B.; Jia, Y.; Zhang, L.; Yang, G.; Shao, H.; Jiang, X. Pharmaceutical Intermediate Modified Gold Nanoparticles: Against Multidrug-Resistant Bacteria and Wound-Healing Application via an Electrospun Scaffold. ACS Nano 2017, 11, 5737-5745. [CrossRef]

11. Roopalakshmi, S.; Ravishankar, R.; Belaldavar, S.; Prasad, R.G.S.V.; Phani, A.R. Investigation of structural and morphological characteristic of hydroxyapatite synthesized by sol-gel process. Mater. Today Proc. 2017, 4, 12026-12031. [CrossRef]

12. Loo, S.C.J.; Moore, T.; Banik, B.; Alexis, F. Biomedical applications of hydroxyapatite nanoparticles. Curr. Pharm. Biotechnol. 2010, 11, 333-342. [CrossRef] 
13. Hirai, S.; Nishinaka, K.; Shimakage, K.; Uo, M.; Watari, F. Hydroxyapatite coating on titanium substrate by the sol-gel process. J. Am. Ceram. Soc. 2004, 87, 29-34. [CrossRef]

14. Jones, J.R.; Lin, S.; Yue, S.; Lee, P.D.; Hanna, J.V.; Smith, M.E.; Newport, R.J. Bioactive glass scaffolds for bone regeneration and their hierarchical characterization. Proc. Inst. Mech. Eng. Part H J. Eng. Med. 2010, 224, 1373-1387. [CrossRef] [PubMed]

15. Webster, T.J.; Ergun, C.; Doremus, R.H.; Bizios, R. Hydroxylapatite with substituted magnesium, zinc, cadmium and yttrium. II. Mechanisms of osteoblast adhesion. J. Biomed. Mater. Res. 2002, 59, 312-317. [CrossRef]

16. Yasukawa, A.; Gotoh, K.; Tanaka, H.; Kandori, K. Preparation and structure of calcium hydroxyapatite substituted with light rare earth ions. Colloids Surf. A 2012, 393, 53-59. [CrossRef]

17. Kim, T.N.; Feng, Q.L.; Kim, J.O.; Wu, J.; Wang, H.; Chen, G.C.; Cui, F.Z. Antimicrobial effects of metal ions $\left(\mathrm{Ag}^{+}, \mathrm{Cu}^{2+}, \mathrm{Zn}^{2+}\right)$ in hydroxyapatite. J. Mater. Sci. Mater. Med. 1998, 9, 129-134. [CrossRef] [PubMed]

18. Lin, Y.; Yang, Z.; Cheng, J. Preparation, characterization and antibacterial property of cerium substituted hydroxyapatite nanoparticles. J. Rare Earths 2007, 25, 452-456.

19. Bigi, A.; Boanini, E.; Capuccini, C.; Gazzano, M. Strontium-substituted hydroxyapatite nanocrystals. Inorg. Chim. Acta 2007, 360, 1009-1116. [CrossRef]

20. Kolekar, T.V.; Thorat, N.D.; Yadav, H.M.; Magalad, V.T.; Shinde, M.A.; Bandgar, S.; Kim, J.H.; Agawane, G.L. Nanocrystalline hydroxyapatite doped with aluminium: A potential carrier for biomedical applications. Ceram. Int. 2016, 42, 5304-5311. [CrossRef]

21. Nordström, E.G.; Karlsson, K.H. Chemical Characterization of a Potassium Hydroxyapatite Prepared by Soaking in Potassium Chloride and Carbonate Solutions. Bio-Med. Mater. Eng. 1992, 2, 185-189. [CrossRef]

22. Yuntao, W.; Guohao, R.; Dongzhou, D.; Fan, Y.; Shangke, P. Study on the cerium oxidation state in a Lu0.8Sc0.2BO3 host. J. Mater. Chem. 2011, 21, 17805-17809. [CrossRef]

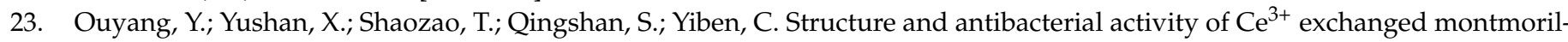
lonites. J. Rare Earths 2009, 27, 858-863. [CrossRef]

24. Predoi, D.; Iconaru, S.L.; Predoi, M.V.; Groza, A.; Gaiaschi, S.; Rokosz, K.; Raaen, S.; Negrila, C.C.; Prodan, A.-M.; Costescu, A.; et al. Development of Cerium-Doped Hydroxyapatite Coatings with Antimicrobial Properties for Biomedical Applications. Coatings 2020, 10, 516. [CrossRef]

25. Bornside, D.E.; Macosko, C.W.; Scriven, L.E. Chemical Engineering and Materials Science. J. Imaging Technol. 1987, $13,122-130$.

26. Predoi, D.; Iconaru, S.L.; Predoi, M.V.; Motelica-Heino, M.; Buton, N.; Megier, C. Obtaining and Characterizing Thin Layers of Magnesium Doped Hydroxyapatite by Dip Coating Procedure. Coatings 2020, 10, 510. [CrossRef]

27. Prodan, A.M.; Iconaru, S.L.; Predoi, M.V.; Predoi, D.; Motelica-Heino, M.; Turculet, C.S.; Beuran, M. Silver-Doped Hydroxyapatite Thin Layers Obtained by Sol-Gel Spin Coating Procedure. Coatings 2020, 10, 14. [CrossRef]

28. Predoi, D.; Iconaru, S.L.; Predoi, M.V.; Motelica-Heino, M.; Guegan, R.; Buton, N. Evaluation of Antibacterial Activity of Zinc-Doped Hydroxyapatite Colloids and Dispersion Stability Using Ultrasounds. Nanomaterials 2019, 9, 515. [CrossRef] [PubMed]

29. ImageJ. Available online: http:/ /imagej.nih.gov/ij (accessed on 10 January 2018).

30. Gwyddion. Available online: http://gwyddion.net/ (accessed on 20 January 2020).

31. CasaXPS: Processing Software for XPS, AES, SIMS and More, Copyright @ 2009 Casa Software Ltd. Available online: www. casaxps.com (accessed on 12 February 2021).

32. Biesinger, M.C.; Lau, L.W.M.; Gerson, A.R.; Smart, R.S.C. Resolving surface chemical states in XPS analysis of first row transition metals, oxides and hydroxides: Sc, Ti, V, Cu and Zn. Appl. Surf. Sci. 2010, 257, 887-898. [CrossRef]

33. Wagner, C.D.; Naumkin, A.V.; Kraut-Vass, A.; Allison, J.W.; Powell, C.J.; Rumble, J.R., Jr. NIST Standard Reference Database 20, Version 3.4. 2003. Available online: Srdata.nist.gov/xps (accessed on 20 January 2021).

34. Iconaru, S.L.; Groza, A.; Stan, G.E.; Predoi, D.; Gaiaschi, S.; Trusca, R.; Chifiriuc, C.M.; Marutescu, L.; Tite, T.; Stanciu, G.A.; et al. Preparations of Silver/Montmorillonite Biocomposite Multilayers and Their Antifungal Activity. Coatings 2019, 9, 817. [CrossRef]

35. Iconaru, S.L.; Prodan, A.M.; Turculet, C.S.; Beuran, M.; Ghita, R.V.; Costescu, A.; Groza, A.; Chifiriuc, M.C.; Chapon, P.; Gaiaschi, S.; et al. Enamel based composite layers deposited on titanium substrate with antifungal activity. J. Spectrosc. 2016, 2016, 4361051. [CrossRef]

36. ASTM International. ASTM E2149-13a Standard Test Method for Determining the Antimicrobial Activity of Antimicrobial Agents under Dynamic Contact Conditions; ASTM International: West Conshohocken, PA, USA, 2013.

37. Fuchs, A.V.; Ritz, S.; Pütz, S.; Mailänder, V.; Landfester, K.; Ziener, U. Bioinspired phosphorylcholine containing polymer films with silver nanoparticles combining antifouling and antibacterial properties. Biomater. Sci. 2013, 1, 470-477. [CrossRef]

38. Predoi, D.; Iconaru, S.L.; Predoi, M.V.; Buton, N.; Motelica-Heino, M. Zinc doped hydroxyapatite thin films prepared by sol-gel spin coating procedure. Coatings 2019, 9, 156. [CrossRef]

39. Rusu, V.M.; Ng, C.H.; Wilke, M.; Tiersch, B.; Fratzl, P.; Peter, M.G. Size controlled hydroxyapatite nanoparticles as self-organised organic-inorganic composite materials. Biomaterials 2005, 26, 5414-5426. [CrossRef]

40. Danilchenko, S.N.; Kukharenko, O.G.; Moseke, C.; Protsenko, I.Y.; Sukhodub, L.F.; Sulkio-Cleff, B. Determinat ion of the bone mineral crystallite size and lattice strain from diffraction line broadening. Cryst. Res. Technol. 2002, 37, 1234-1240. [CrossRef]

41. Klug, H.P.; Alexander, L.E. X-Ray Diffraction Procedures for Polycrystallite and Amorphous Materials, 2nd ed.; Wiley: New York, NY, USA, 1974. 
42. Barrett, C.S.; Cohen, J.B.; Faber, J.; Jenkins, R.; Leyden, D.E.; Russ, J.C.; Predecki, P.K. Advances in X-ray Analysis, Vol. 29; Plenum Press: New York, NY, USA, 1986.

43. Rincón-López, J.A.; Hermann-Muñoz, J.A.; Giraldo-Betancur, A.L.; De Vizcaya-Ruiz, A.; Alvarado-Orozco, J.M.; Muñoz-Saldaña, J. Synthesis, Characterization and In Vitro Study of Synthetic and Bovine-Derived Hydroxyapatite Ceramics: A Comparison. Materials 2018, 11, 333. [CrossRef]

44. Kulanthaivel, S.; Roy, B.; Agarwal, T.; Giri, S.; Pramanik, K.; Pal, K.; Ray, S.S.; Maiti, T.K.; Banerjee, I. Cobalt doped proangiogenic hydroxyapatite for bone tissue engineering application. Mater. Sci. Eng. C 2016, 58, 648-658. [CrossRef] [PubMed]

45. De Carolis, S.; Pascual, J.L.; Pettersson, L.G.M.; Baudin, M.; Hermansson, K.; Palmqvist, A.E.C.; Muhammed, M. Structure and electronic properties of $\mathrm{Ca}$-doped $\mathrm{CeO}_{2}$ and implications on catalytic activity: An experimental and theoretical study. J. Phys. Chem. B 1999, 103, 7627-7636. [CrossRef]

46. Della Mea, G.B.; Matte, L.P.; Thill, A.S.; Lobato, F.O.; Benvenutti, E.V.; Arenas, L.T.; Jürgensen, A.; Hergenröder, R.; Poletto, F.; Bernardi, F. Tuning the oxygen vacancy population of cerium oxide (CeO2-x, $0<\mathrm{x}<0.5)$ nanoparticles. Appl. Surf. Sci. 2017, 422, 1102-1112. [CrossRef]

47. Lu, H.B.; Campbell, C.T.; Graham, D.J.; Ratner, B.D. Surface characterization of hydroxyapatite and related calcium phosphates by XPS and TOF-SIMS. Anal. Chem. 2000, 72, 2886-2894. [CrossRef] [PubMed]

48. Kaciulis, S.; Mattogno, G.; Pandolfi, L.; Cavalli, M.; Gnappi, G.; Montenero, A. XPS study of apatite-based coatings prepared by sol-gel technique. Appl. Surf. Sci. 1999, 151, 1-5. [CrossRef]

49. Fazan, F.; Marquis, P.M. Dissolution behavior of plasma-sprayed hydroxyapatite coatings. J. Mater. Sci. Mater. Med. 2000, 11, 787-792. [CrossRef]

50. Phatai, P.; Futalan, C.M.; Utara, S.; Khemthong, P.; Kamonwannasit, S. Structural characterization of cerium-doped hydroxyapatite nanoparticles synthesized by an ultrasonic-assisted sol-gel technique. Results Phys. 2018, 10, 956-963. [CrossRef]

51. Shimizu, K.; Habazaki, H.; Skeldon, P.; Thompson, G.E. Radiofrequency GDOES: A powerful technique for depth profiling analysis of thin films. Surf. Interface Anal. 2003, 35, 564-574. [CrossRef]

52. Ciobanu, C.S.; Popa, C.L.; Predoi, D. Cerium-doped hydroxyapatite nanoparticles synthesized by the co-precipitation method. J. Serb. Chem. Soc. 2016, 81, 433-446. [CrossRef]

53. Kolmas, J.; Groszyk, E.; Kwiatkowska-Różycka, D. Substituted Hydroxyapatites with Antibacterial Properties. BioMed Res. Int. 2014, 2014, 1-15. [CrossRef] [PubMed]

54. Dai, G.; Yu, A.; Cai, X.; Shi, Q.; Ouyang, Y.; Tan, S. Synthesis, characterization and antimicrobial activity of zinc and cerium co-doped $\alpha$-zirconium phosphate. J. Rare Earths 2012, 30, 820-825. [CrossRef]

55. Passos Farias, I.A.; Lima dos Santos, C.C.; Correia Sampaio, F. Antimicrobial Activity of Cerium Oxide Nanoparticles on Opportunistic Microorganisms: A Systematic Review. BioMed Res. Int. 2018, 2018, 1923606.

56. Ciobanu, G.; Harja, M. Cerium-doped hydroxyapatite/collagen coatings on titanium for bone implants. Ceram. Int. 2019, 4, 2852-2857. [CrossRef]

57. Dahle, J.T.; Arai, Y. Environmental geochemistry of cerium: Applications and toxicology of cerium oxide nanoparticles. Int. J. Environ. Res. Public Health 2015, 12, 1253-1278. [CrossRef]

58. Wang, Y.Z.; Xue, X.X.; Yang, H. Preparation and characterization of zinc and cerium co-doped titania nano-materials with antibacterial activity. J. Inorg. Mater. 2013, 28, 117-122. [CrossRef]

59. Tsui, C.; Kong, E.F.; Jabra-Rizk, M.A. Pathogenesis of Candida albicans biofilm. Pathog. Dis. 2016, 74, ftw018. [CrossRef]

60. Iconaru, S.L.; Prodan, A.M.; Buton, N.; Predoi, D. Structural characterization and antifungal studies of Zinc-doped hydroxyapatite coatings. Molecules 2017, 22, 604. [CrossRef] [PubMed]

61. Ciobanu, S.C.; Iconaru, S.L.; Predoi, D.; Prodan, A.M.; Predoi, M.V. Physico-Chemical Properties and In Vitro Antifungal Evaluation of Samarium Doped Hydroxyapatite Coatings. Coatings 2020, 10, 827. [CrossRef]

62. Sekyere, J.O.; Asante, J. Emerging mechanisms of antimicrobial resistance in bacteria and fungi: Advances in the era of genomics. Future Microbiol. 2018, 13. [CrossRef] [PubMed]

63. Available online: https://www.cdc.gov/drugresistance/about/how-resistance-happens.html (accessed on 7 April 2021).

64. Wang, L.; Hu, C.; Shao, L. The antimicrobial activity of nanoparticles: Present situation and prospects for the future. Int. J. Nanomed. 2017, 12, 1227-1249. [CrossRef] [PubMed]

65. Yu, J.; Zhang, W.; Li, Y.; Wang, G.; Yang, L.; Jin, J.; Chen, Q.; Huang, M. Synthesis, characterization, antimicrobial activity and mechanism of a novel hydroxyapatite whisker/nano zinc oxide biomateriali. Biomed. Mater. 2014, 10, 015001. [CrossRef] [PubMed]

66. Lesniak, A.; Salvati, A.; Santos-Martinez, M.J.; Radomski, M.W.; Dawson, K.A.; Åberg, C. Nanoparticle adhesion to the cell membrane and its effect on nano-particle uptake efficiency. J. Am. Chem. Soc. 2013, 135, 1438-1444. [CrossRef]

67. Sarwar, A.; Katas, H.; Samsudin, S.N.; Zin, N.M. Regioselective sequential modification of chitosan via azide-alkyne click reaction: Synthesis, characterization, and antimicrobial activity of ahitosan derivatives and nanoparticles. PLoS ONE 2015, 10, e0123084. [CrossRef]

68. Navale, G.R.; Thripuranthaka, M.; Late, D.J.; Shinde, S.S. Antimicrobial Activity of ZnO Nanoparticles against Pathogenic Bacteria and Fungi. JSM Nanotechnol Nanomed 2015, 3, 1033.

69. Pan, X.; Wang, Y.; Chen, Z.; Pan, D.; Cheng, Y.; Liu, Z.; Lin, Z.; Guan, X. Investigation of antibacterial activity and related mechanism of a series of nano- $\mathrm{Mg}(\mathrm{OH})_{2}$. ACS Appl. Mater. Interfaces 2013, 5, 1137-1142. [CrossRef] 
70. Lin, N.; Berton, P.; Moraes, C.; Rogers, R.D.; Tufenkji, N. Nanodarts, nanoblades, and nanospikes: Mechano-bactericidal nanostructures and where to find them. Adv. Coll. Interface Sci. 2018, 252, 55-68. [CrossRef]

71. Ellinas, K.; Kefallinou, D.; Stamatakis, K.; Gogolides, E.; Tserepi, A. There a Threshold in the Antibacterial Action of Superhydrophobic Surfaces? ACS Appl. Mater. Interface 2017, 9, 39781-39789. [CrossRef]

72. Ben-Sasson, M.; Zodrow, K.R.; Genggeng, Q.; Kang, Y.; Giannelis, E.P.; Elimelech, M. Surface functionalization of thin-film composite membranes with copper nanoparticles for antimicrobial surface properties. Environ. Sci. Technol. 2014, 48, 384-393. [CrossRef]

73. Rajakumar, G.; Rahuman, A.A.; Roopan, S.M.; Khanna, V.G.; Elango, G.; Kamaraj, C.; Zahir, A.A.; Velayutham, K. Fungusmediated biosynthesis and characterization of $\mathrm{TiO} 2$ nanoparticles and their activity against pathogenic bacteria. Spectrochim. Acta A Mol. Biomol. Spectrosc. 2012, 91, 23-29. [CrossRef] [PubMed]

74. Sukhorukova, I.V.; Sheveyko, A.N.; Kiryukhantsev-Korneev, P.V.; Zhitnyak, I.Y.; Gloushankova, N.A.; Denisenko, E.A.; Filippovich, S.Y.; Ignatov, S.G.; Shtansky, D.V. Toward bioactive yet antibacterial surfaces. Colloid Surf. B 2015, 135, $158-165$. [CrossRef]

75. Kim, K.-I.; Kim, D.-A.; Patel, K.D.; Shin, U.S.; Kim, H.-W.; Lee, J.-H.; Lee, H.-H. Carbon nanotube incorporation in PMMA to prevent microbial adhesion. Sci. Rep. 2019, 9, 4921. [CrossRef]

76. Lagree, K.; Mon, H.H.; Mitchell, A.P.; Ducker, W.A. Impact of surface topography on biofilm formation by Candida albicans. PLoS ONE 2018, 13, e0197925. [CrossRef] [PubMed]

77. Villard, N.; Seneviratne, C.; Tsoi, J.K.H.; Heinonen, M.; Matinlinna, J. Candida albicans aspects of novel silane system-coated titanium and zirconia implant surfaces. Clin. Oral Implants Res. 2015, 26, 332-341. [CrossRef] [PubMed]

78. Mayahara, M.; Kataoka, R.; Arimoto, T.; Tamaki, Y.; Yamaguchi, N.; Watanabe, Y.; Yamasaki, Y.; Miyazaki, T. Effects ofsurface roughness and dimorphism on the adhesion of Candida albicans to the surface of resins: Scanning electron microscopeanalyses of mode and number of adhesions. J. Investig. Clin. Dent. 2014, 5, 307-312. [CrossRef]

79. Le, P.H.; Nguyen, D.H.K.; Aburto-Medina, A.; Linklater, D.P.; Crawford, R.J.; MacLaughlin, S.; Ivanova, E.P. Nanoscale Surface Roughness Influences Candida albicans Biofilm Formation. ACS Appl. Bio Mater. 2020, 3, 8581-8591. [CrossRef] 